\title{
Prevention and Control of Seasonal Influenza
} with Vaccines: Recommendations of the Advisory Committee on Immunization Practices United States, 2019-20 Influenza Season 


\section{CONTENTS}

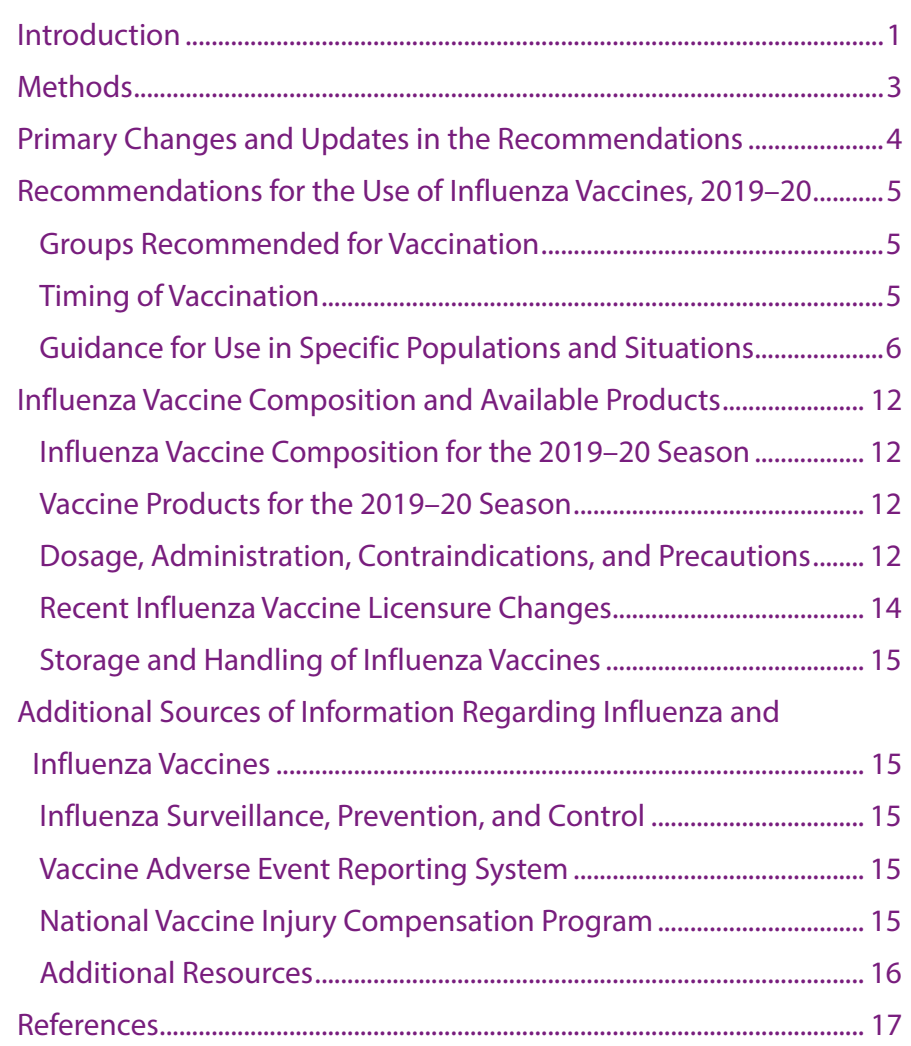

\section{CDC Adoption of ACIP Recommendations for MMWR Recommendations and Reports, MMWR Policy Notes, and Immunization Schedules (Child/Adolescent, Adult)}

Recommendations for routine use of vaccines in children, adolescents, and adults are developed by the Advisory Committee on Immunization Practices (ACIP). ACIP is chartered as a Federal Advisory Committee to provide expert external advice and guidance to the Director of CDC on use of vaccines and related agents for the control of vaccine preventable diseases in the civilian population of the United States. Recommendation for routine use of vaccines in children and adolescents are harmonized to the greatest extent possible with recommendations made by the American Academy of Pediatrics (AAP), the American Academy of Family Physicians (AAFP), and the American College of Obstetricians and Gynecologists (ACOG). Recommendations for routine use of vaccinations in adults are harmonized with recommendations of AAFP, ACOG, and the American College of Physicians (ACP). ACIP recommendations approved by the CDC Director become agency guidelines on the date published in the Morbidity and Mortality Weekly Report (MMWR). Additional information is available at https://www.cdc.gov/vaccines/acip.

The MMWR series of publications is published by the Center for Surveillance, Epidemiology, and Laboratory Services, Centers for Disease Control and Prevention (CDC), U.S. Department of Health and Human Services, Atlanta, GA 30329-4027.

Suggested citation: [Author names; first three, then et al., if more than six.] [Title]. MMWR Recomm Rep 2019;68(No. RR-\#):[inclusive page numbers].

\section{Centers for Disease Control and Prevention}

Robert R. Redfield, MD, Director

Anne Schuchat, MD, Principal Deputy Director

Chesley L. Richards, MD, MPH, Deputy Director for Public Health Science and Surveillance

Rebecca Bunnell, PhD, MEd, Director, Office of Science Barbara Ellis, PhD, MS, Acting Director, Office of Science Quality, Office of Science

Michael F. Iademarco, MD, MPH, Director, Center for Surveillance, Epidemiology, and Laboratory Services

MMWR Editorial and Production Staff (Serials)

Charlotte K. Kent, PhD, MPH, Editor in Chief Christine G. Casey, MD, Editor

Mary Dott, MD, MPH, Online Editor

Terisa F. Rutledge, Managing Editor

David C. Johnson, Lead Technical Writer-Editor

Catherine B. Lansdowne, MS, Project Editor

Matthew L. Boulton, MD, MPH Virginia A. Caine, MD

Katherine Lyon Daniel, $\mathrm{PhD}$

Jonathan E. Fielding, MD, MPH, MBA

David W. Fleming, MD

William E. Halperin, MD, DrPH, MPH
MMWR Editorial Board

Timothy F. Jones, MD, Chairman

Robin Ikeda, MD, MPH

Phyllis Meadows, PhD, MSN, RN

Jewel Mullen, MD, MPH, MPA

Jeff Niederdeppe, PhD

Patricia Quinlisk, MD, MPH
Martha F. Boyd, Lead Visual Information Specialist Maureen A. Leahy, Julia C. Martinroe, Stephen R. Spriggs, Tong Yang, Visual Information Specialists

Quang M. Doan, MBA, Phyllis H. King, Terraye M. Starr, Moua Yang, Information Technology Specialists

Stephen C. Redd, MD

Patrick L. Remington, MD, MPH

Carlos Roig, MS, MA

William Schaffner, MD

Morgan Bobb Swanson, BS 


\title{
Prevention and Control of Seasonal Influenza with Vaccines: Recommendations of the Advisory Committee on Immunization Practices - United States, 2019-20 Influenza Season
}

\author{
Lisa A. Grohskopf, MD ${ }^{1}$; Elif Alyanak, MPH${ }^{1,2}$; Karen R. Broder, $\mathrm{MD}^{3}$; Emmanuel B. Walter, MD ${ }^{4}$; Alicia M. Fry, MD ${ }^{1}$; Daniel B. Jernigan, MD ${ }^{1}$ \\ ${ }^{1}$ Influenza Division, National Center for Immunization and Respiratory Diseases, CDC; ${ }^{2}$ Battelle Memorial Institute, Atlanta, Georgia; ${ }^{3}$ Immunization Safety \\ Office, National Center for Emerging and Zoonotic Infectious Diseases, CDC; ${ }^{4}$ Duke University School of Medicine, Durham, North Carolina
}

\section{Summary}

This report updates the 2018-19 recommendations of the Advisory Committee on Immunization Practices (ACIP) regarding the use of seasonal influenza vaccines in the United States (MMWR Recomm Rep 2018;67[No. RR-3]). Routine annual influenza vaccination is recommended for all persons aged $\geq 6$ months who do not have contraindications. A licensed, recommended, and age-appropriate vaccine should be used. Inactivated influenza vaccines (IIVs), recombinant influenza vaccine (RIV), and live attenuated influenza vaccine (LAIV) are expected to be available for the 2019-20 season. Standard-dose, unadjuvanted, inactivated influenza vaccines will be available in quadrivalent formulations (IIV4s). High-dose (HD-IIV3) and adjuvanted (aIIV3) inactivated influenza vaccines will be available in trivalent formulations. Recombinant (RIV4) and live attenuated influenza vaccine (LAIV4) will be available in quadrivalent formulations.

Updates to the recommendations described in this report reflect discussions during public meetings of ACIP held on October 25, 2018; February 27, 2019; and June 27, 2019. Primary updates in this report include the following two items. First, 2019-20 U.S. trivalent influenza vaccines will contain hemagglutinin (HA) derived from an A/Brisbane/02/2018 (H1N1)pdm09-like virus, an A/Kansas/14/2017 (H3N2)-like virus, and a B/Colorado/06/2017-like virus (Victoria lineage). Quadrivalent influenza vaccines will contain HA derived from these three viruses, and a B/Phuket/3073/2013-like virus (Yamagata lineage). Second, recent labeling changes for two IIV4s, Afluria Quadrivalent and Fluzone Quadrivalent, are discussed. The age indication for Afluria Quadrivalent has been expanded from $\geq 5$ years to $\geq 6$ months. The dose volume for Afluria Quadrivalent is $0.25 \mathrm{~mL}$ for children aged 6 through 35 months and $0.5 \mathrm{~mL}$ for all persons aged $\geq 36$ months ( $\geq 3$ years). The dose volume for Fluzone Quadrivalent for children aged 6 through 35 months, which was previously $0.25 \mathrm{~mL}$, is now either $0.25 \mathrm{~mL}$ or $0.5 \mathrm{~mL}$. The dose volume for Fluzone Quadrivalent is $0.5 \mathrm{~mL}$ for all persons aged $\geq 36$ months ( $\geq 3$ years).

This report focuses on the recommendations for use of vaccines for the prevention and control of influenza during the 2019-20 season in the United States. A brief summary of these recommendations and a Background Document containing additional information are available at https://www.cdc.gov/vaccines/hcplacip-recs/vacc-specificlflu. html. These recommendations apply to U.S.-licensed influenza vaccines used within Food and Drug Administration-licensed indications. Updates and other information are available from CDC's influenza website (https://www.cdc.gov/flu). Vaccination and health care providers should check this site periodically for additional information.

\section{Introduction}

Influenza viruses typically circulate in the United States annually, most commonly from late fall through early spring. Most persons who contract influenza recover without serious complications or sequelae. However, influenza can result in serious illness, hospitalization, and death, particularly among older adults, very young children, pregnant women, and persons with certain chronic medical conditions (1-7). Influenza illness also is an important cause of missed work and school $(8-10)$. Routine annual influenza vaccination for all persons aged $\geq 6$ months who do not have contraindications has

Corresponding author: Lisa A. Grohskopf, Influenza Division, National Center for Immunization and Respiratory Diseases, CDC. Telephone: 404-639-2552; E-mail: lgrohskopf@cdc.gov. been recommended by CDC and CDC's Advisory Committee on Immunization Practices (ACIP) since 2010 (11).

The effectiveness of influenza vaccines varies depending on several factors, such as the age and health of the recipient, the types and subtypes of circulating influenza viruses, and the degree of similarity between circulating viruses and those included in the vaccine (12). However, vaccination provides important protection from influenza illness and its potential complications. During the six influenza seasons from 2010-11 through 2015-16, influenza vaccination prevented an estimated 1.6-6.7 million illnesses, 790,000-3.1 million outpatient medical visits, 39,000-87,000 hospitalizations, and 3,000-10,000 respiratory and circulatory deaths each season in the United States (13). During the recent severe 2017-18 influenza season, notable for an unusually long duration of widespread high influenza activity throughout the United States and higher rates of outpatient visits and 
hospitalizations compared with recent seasons, vaccination is estimated to have prevented 7.1 million illnesses, 3.7 million medical visits, 109,000 hospitalizations, and 8,000 deaths (14), despite an overall estimated vaccine effectiveness of $38 \%$ (62\% against influenza $\mathrm{A}[\mathrm{H} 1 \mathrm{~N} 1] \mathrm{pdm} 09$ viruses, $22 \%$ against influenza $A[H 3 N 2]$ viruses, and $50 \%$ against influenza $B$ viruses).

This report updates the 2018-19 ACIP recommendations regarding the use of seasonal influenza vaccines $(15)$ and provides recommendations and guidance for vaccine providers regarding the use of influenza vaccines for the 2019-20 season. Various formulations of influenza vaccines are available (Table 1).
Contraindications and precautions to the use of influenza vaccines are summarized (Table 2). Abbreviations are used in this report to denote the various types of vaccines (Box).

This report focuses on recommendations and guidance for the use of influenza vaccines for the prevention and control of influenza in the United States. A summary of these recommendations and a Background Document containing additional information on influenza, influenza-associated illness, and influenza vaccines are available at https://www.cdc. gov/vaccines/hcp/acip-recs/vacc-specific/flu.html.

TABLE 1. Influenza vaccines — United States, 2019-20 influenza season*

\begin{tabular}{|c|c|c|c|c|c|}
\hline Trade name (Manufacturer) & Presentation & Age indication & $\begin{array}{l}\text { HA (IIVs and RIV4) or virus } \\
\text { count (LAIV4) for each vaccine } \\
\text { virus (per dose) }\end{array}$ & Route & $\begin{array}{c}\text { Mercury (from } \\
\text { thimerosal) } \\
(\mu \mathrm{g} / 0.5 \mathrm{~mL})\end{array}$ \\
\hline \multicolumn{6}{|l|}{ IIV4-Standard Dose-Egg based ${ }^{\dagger}$} \\
\hline Afluria Quadrivalent (Seqirus) & $\begin{array}{l}0.25-\mathrm{mL} P F S^{\S} \\
0.5-\mathrm{mL} P F S^{\S} \\
5.0-\mathrm{mL} \mathrm{MDV} \S\end{array}$ & $\begin{array}{l}6 \text { through } 35 \text { mos } \\
\geq 3 \text { yrs } \\
\geq 6 \text { mos (needle/syringe) } \\
18 \text { through } 64 \text { yrs } \\
\text { (jet injector) }\end{array}$ & $\begin{array}{l}7.5 \mu \mathrm{g} / 0.25 \mathrm{~mL}^{\S} \\
15 \mu \mathrm{g} / 0.5 \mathrm{~mL}^{\S}\end{array}$ & IMף & $\frac{-}{24.5}$ \\
\hline Fluarix Quadrivalent (GlaxoSmithKline) & $0.5-\mathrm{mL} P F S$ & $\geq 6 \operatorname{mos}$ & $15 \mu \mathrm{g} / 0.5 \mathrm{~mL}$ & $\mathrm{IM}^{\text {थ }}$ & - \\
\hline FluLaval Quadrivalent (GlaxoSmithKline) & $\begin{array}{l}\text { 0.5-mL PFS } \\
\text { 5.0-mL MDV }\end{array}$ & $\begin{array}{l}\geq 6 \mathrm{mos} \\
\geq 6 \mathrm{mos}\end{array}$ & $15 \mu \mathrm{g} / 0.5 \mathrm{~mL}$ & $\mathrm{IM}^{\text {श }}$ & $-\frac{-}{<25}$ \\
\hline Fluzone Quadrivalent (Sanofi Pasteur) & $\begin{array}{l}\text { 0.25-mL PFS** } \\
0.5-\mathrm{mL} \mathrm{PFS}^{* *} \\
0.5-\mathrm{mL} \mathrm{SDV}^{* *} \\
\text { 5.0-mL MDV** }\end{array}$ & $\begin{array}{l}6 \text { through } 35 \mathrm{mos} \\
\geq 6 \mathrm{mos} \\
\geq 6 \mathrm{mos} \\
\geq 6 \mathrm{mos}\end{array}$ & $\begin{array}{l}7.5 \mu \mathrm{g} / 0.25 \mathrm{~mL}^{* *} \\
15 \mu \mathrm{g} / 0.5 \mathrm{~mL}^{* *}\end{array}$ & $\mathrm{IM}^{\text {थ }}$ & $\begin{array}{l}- \\
\frac{-}{25}\end{array}$ \\
\hline \multicolumn{6}{|c|}{ IIV4-Standard Dose-Cell culture based (cclIV4) } \\
\hline Flucelvax Quadrivalent (Seqirus) & $\begin{array}{l}\text { 0.5-mL PFS } \\
\text { 5.0-mL MDV }\end{array}$ & $\begin{array}{l}\geq 4 \mathrm{yrs} \\
\geq 4 \mathrm{yrs}\end{array}$ & $15 \mu \mathrm{g} / 0.5 \mathrm{~mL}$ & $\mathrm{IM}^{\text {था }}$ & $\overline{25}$ \\
\hline $\begin{array}{l}\text { IIV3-High Dose-Egg based }{ }^{\dagger} \text { (HD-IIV3) } \\
\text { Fluzone High-Dose (Sanofi Pasteur) }\end{array}$ & $0.5-\mathrm{mL}$ PFS & $\geq 65$ yrs & $60 \mu \mathrm{g} / 0.5 \mathrm{~mL}$ & $\mathrm{IM}^{\text {था }}$ & - \\
\hline $\begin{array}{l}\text { IIV3-Standard Dose-Egg based }{ }^{\dagger} \text { with } \\
\text { Fluad (Seqirus) }\end{array}$ & $\begin{array}{l}9 \text { adjuvant (allV3) } \\
0.5-\mathrm{mL} \text { PFS }\end{array}$ & $\geq 65$ yrs & $15 \mu \mathrm{g} / 0.5 \mathrm{~mL}$ & $\mathrm{IM}^{\uparrow}$ & - \\
\hline $\begin{array}{l}\text { RIV4-Recombinant HA } \\
\text { Flublok Quadrivalent (Sanofi Pasteur) }\end{array}$ & $0.5-\mathrm{mL}$ PFS & $\geq 18 \mathrm{yrs}$ & $45 \mu \mathrm{g} / 0.5 \mathrm{~mL}$ & $\mathrm{IM}$ & - \\
\hline $\begin{array}{l}\text { LAIV4-Egg based }{ }^{\dagger} \\
\text { FluMist Quadrivalent (AstraZeneca) }^{\text {(A) }}\end{array}$ & $\begin{array}{l}0.2-\mathrm{mL} \\
\text { prefilled single-use } \\
\text { intranasal sprayer }\end{array}$ & 2 through 49 yrs & $\begin{array}{l}10^{6.5-7.5} \\
\text { fluorescent focus } \\
\text { units } / 0.2 \mathrm{~mL}\end{array}$ & NAS & - \\
\hline
\end{tabular}

Abbreviations: ACIP = Advisory Committee on Immunization Practices; FDA = Food and Drug Administration; $\mathrm{HA}=$ hemagglutinin; IIV3 = inactivated influenza vaccine trivalent; IIV4 = inactivated influenza vaccine, quadrivalent, IM = intramuscular; LAIV4 = live attenuated influenza vaccine, quadrivalent; MDV = multidose vial; NAS = intranasal; PFS = prefilled syringe; RIV4 = recombinant influenza vaccine, quadrivalent; SDV = single-dose vial.

* Vaccination providers should consult FDA-approved prescribing information for 2019-20 influenza vaccines for the most complete and updated information, including (but not limited to) indications, contraindications, warnings, and precautions. Package inserts for U.S.-licensed vaccines are available at https://www.fda. gov/vaccines-blood-biologics/approved-products/vaccines-licensed-use-united-states. Availability of specific products and presentations might change and differ from what is described in this table and in the text of this report.

t Persons with a history of egg allergy may receive any licensed, recommended influenza vaccine that is otherwise appropriate for their age and health status. Those who report having had reactions to egg involving symptoms other than urticaria (e.g., angioedema or swelling, respiratory distress, lightheadedness, or recurrent emesis) or who required epinephrine or another emergency medical intervention should be vaccinated in an inpatient or outpatient medical setting (including, but not necessarily limited to, hospitals, clinics, health departments, and physician offices). Vaccine administration should be supervised by a health care provider who is able to recognize and manage severe allergic reactions.

$\S$ The dose volume for Afluria Quadrivalent is $0.25 \mathrm{~mL}$ for children aged 6 through 35 months and $0.5 \mathrm{~mL}$ for persons aged $\geq 3$ years.

" Intramuscularly-administered influenza vaccines should be given by needle and syringe only, with the exception of the MDV presentation of Afluria Quadrivalent, which may alternatively be given by the PharmaJet Stratis jet injector for persons aged 18 through 64 years only. For adults and older children, the recommended site for IM influenza vaccination is the deltoid muscle. The preferred site for infants and young children is the anterolateral aspect of the thigh. Additional guidance regarding site selection and needle length for intramuscular administration is available in the ACIP General Best Practice Guidelines for Immunization (https:// www.cdc.gov/vaccines/hcp/acip-recs/general-recs/downloads/general-recs.pdf).

** Fluzone Quadrivalent may be given to children aged 6 through 35 months as either $0.25 \mathrm{~mL}$ per dose or $0.5 \mathrm{~mL}$ per dose. No preference is expressed for one or the other dose volume for this age group. Persons aged $\geq 3$ years should receive the $0.5-\mathrm{mL}$ dose volume. 
TABLE 2. Contraindications and precautions to the use of influenza vaccines - United States, 2019-20 influenza season*

\begin{tabular}{|c|c|c|}
\hline $\begin{array}{l}\text { Vaccine } \\
\text { type }\end{array}$ & $\begin{array}{l}\text { Contraindications and conditions } \\
\text { for which use is not recommended }\end{array}$ & Precautions \\
\hline IIV & $\begin{array}{l}\text { History of severe allergic reaction to any component of the vaccine }{ }^{\dagger} \text { or } \\
\text { to a previous dose of any influenza vaccine }\end{array}$ & $\begin{array}{l}\text { Moderate or severe acute illness with or without fever } \\
\text { History of Guillain-Barré syndrome within } 6 \text { weeks after receipt of } \\
\text { influenza vaccine }\end{array}$ \\
\hline RIV4 & History of severe allergic reaction to any component of the vaccine & $\begin{array}{l}\text { Moderate or severe acute illness with or without fever } \\
\text { History of Guillain-Barré syndrome within } 6 \text { weeks after receipt of } \\
\text { influenza vaccine }\end{array}$ \\
\hline LAIV4 & $\begin{array}{l}\text { History of severe allergic reaction to any component of the vaccine }{ }^{\dagger} \text { or } \\
\text { to a previous dose of any influenza vaccine } \\
\text { Concomitant aspirin- or salicylate-containing therapy in children and } \\
\text { adolescents } \\
\text { Children aged } 2 \text { through } 4 \text { years who have received a diagnosis of } \\
\text { asthma or whose parents or caregivers report that a health care } \\
\text { provider has told them during the past } 12 \text { months that their child had } \\
\text { wheezing or asthma or whose medical record indicates a wheezing } \\
\text { episode has occurred within the past } 12 \text { months } \\
\text { Children and adults who are immunocompromised due to any cause } \\
\text { (including immunosuppression caused by medications or } \\
\text { HIV infection) } \\
\text { Close contacts and caregivers of severely immunosuppressed persons } \\
\text { who require a protected environment } \\
\text { Pregnancy } \\
\text { Receipt of influenza antiviral medication within the past } 48 \text { hours }\end{array}$ & $\begin{array}{l}\text { Moderate or severe acute illness with or without fever } \\
\text { History of Guillain-Barré syndrome within } 6 \text { weeks after receipt of } \\
\text { influenza vaccine } \\
\text { Asthma in persons aged } \geq 5 \text { years } \\
\text { Other underlying medical conditions that might predispose to } \\
\text { complications after wild-type influenza infection (e.g., chronic } \\
\text { pulmonary, cardiovascular [excluding isolated hypertension], renal, } \\
\text { hepatic, neurologic, hematologic, or metabolic disorders [including } \\
\text { diabetes mellitus]) }\end{array}$ \\
\hline
\end{tabular}

Abbreviations: ACIP = Advisory Committee on Immunization Practices; FDA = Food and Drug Administration; IIV = inactivated influenza vaccine; LAIV4 = live-attenuated influenza vaccine, quadrivalent; RIV4 = recombinant influenza vaccine, quadrivalent.

* Vaccination providers should check FDA-approved prescribing information for 2019-20 influenza vaccines for the most complete and updated information, including (but not limited to) indications, contraindications, warnings, and precautions. Package inserts for U.S.-licensed vaccines are available at https://www.fda.gov/ vaccines-blood-biologics/approved-products/vaccines-licensed-use-united-states.

${ }^{\dagger}$ History of severe allergic reaction (e.g., anaphylaxis) to egg is a labeled contraindication to the use of most IIVs and LAIV4. However, ACIP recommends that persons with a history of egg allergy may receive any licensed, recommended influenza vaccine that is otherwise appropriate for their age and health status. Those who report having had reactions to egg involving symptoms other than urticaria (e.g., angioedema or swelling, respiratory distress, lightheadedness, or recurrent emesis) or who required epinephrine or another emergency medical intervention should be vaccinated in an inpatient or outpatient medical setting (including, but not necessarily limited to, hospitals, clinics, health departments, and physician offices). Vaccine administration should be supervised by a health care provider who is able to recognize and manage severe allergic reactions.

\section{BOX. Abbreviation conventions for vaccines discussed in this report}

- Primary influenza vaccine types include the following:

- IIV = inactivated influenza vaccine

- RIV = recombinant influenza vaccine

- LAIV = live attenuated influenza vaccine

- Numerals following letter abbreviations indicate the number of influenza virus hemagglutinin antigens represented in the vaccine:

- 3 for trivalent vaccines: one $\mathrm{A}(\mathrm{H} 1 \mathrm{~N} 1)$, one

$\mathrm{A}(\mathrm{H} 3 \mathrm{~N} 2)$, and one $\mathrm{B}$ virus

- 4 for quadrivalent vaccines: one $\mathrm{A}(\mathrm{H} 1 \mathrm{~N} 1)$, one $\mathrm{A}(\mathrm{H} 3 \mathrm{~N} 2)$, and two $\mathrm{B}$ viruses

- Prefixes are used when necessary to refer to some specific vaccine types:

- a for adjuvanted vaccine (e.g., aIIV3)

- cc for cell culture-based vaccine (e.g., ccIIV4)

- HD for high-dose vaccine (e.g., HD-IIV3)

- SD for standard-dose vaccine (e.g., SD-IIV4)

\section{Methods}

ACIP provides annual recommendations for the use of influenza vaccines for the prevention and control of influenza. The ACIP Influenza Work Group meets by teleconference once to twice per month throughout the year. Work group membership includes several voting members of ACIP, representatives of ACIP Liaison Organizations, and consultants. Discussions include topics such as influenza surveillance, vaccine effectiveness and safety, vaccine coverage, program feasibility, cost-effectiveness, and vaccine supply. Presentations are requested from invited experts, and published and unpublished data are discussed.

In general, the Background Document that supplements this report is updated to reflect recent additions to the literature related to recommendations made in previous seasons and minor changes in guidance for the use of influenza vaccines (e.g., guidance for timing of vaccination and other programmatic issues, guidance for dosage in specific populations, guidance for selection of vaccines for specific populations that are already recommended for vaccination, and changes that reflect use that is consistent with Food and Drug Administration 
[FDA]-licensed indications and prescribing information). The summary included in the Background Document for such topics is not a systematic review but is intended to provide an overview of current literature, with updated articles being identified primarily through a broad search for Englishlanguage articles on influenza and influenza vaccines. In general, systematic review and evaluation of evidence using the Grading of Recommendations Assessment, Development and Evaluation (GRADE) approach is performed for new recommendations or substantial changes in the recommendations (e.g., expansion of the recommendation for influenza vaccination to new populations not previously recommended for vaccination or potential preferential recommendations for specific vaccines).

This report includes no substantial changes from the 2018-19 recommendations. Updates and changes to the recommendations described in this report are of two types: 1) the vaccine virus composition for 2019-20 U.S. seasonal influenza vaccines, and 2) recent regulatory actions, including labeling changes for previously licensed vaccines that occurred after the publication of the 2018-19 ACIP Influenza Vaccine Statement (15). Information relevant to these changes includes the following:

1. Recommendations for the composition of Northern Hemisphere influenza vaccines are made by the World Health Organization (WHO), which organizes a consultation, generally in February of each year. Surveillance data are reviewed and candidate vaccine viruses are discussed. A summary of the WHO meetings of February 21, 2019, and March 21, 2019, for selection of the 2019-20 Northern Hemisphere vaccine viruses is available at https://www.who.int/influenza/vaccines/ virus/recommendations/2019_20_north/en. Subsequently, FDA, which has regulatory authority over vaccines in the United States, convenes a meeting of its Vaccines and Related Biological Products Advisory Committee (VRBPAC). This committee considers the recommendations of WHO, reviews and discusses similar data, and makes a final decision regarding vaccine virus composition of influenza vaccines licensed and marketed in the United States. Summaries of the VRBPAC discussions of March 6, 2019, and March 22, 2019, during which the composition of the 2019-20 U.S. influenza vaccines was discussed, are available at https:// www.fda.gov/advisory-com mit tees/ vaccines-and-related-biological-products-advisorycommittee/2019-meeting-materials-vaccines-andrelated-biological-products-advisory-committee.

2. Regarding recommendations concerning newly licensed influenza vaccines and changes to the licensed indications for existing vaccines, ACIP relies on FDA for review of safety, immunogenicity, and efficacy/effectiveness data pertaining to licensure of influenza vaccines. Regulatory information pertinent to the labeling changes discussed in this reports is available at https://www.fda.gov/ vaccines-blood-biologics/approved-products/afluriaquadrivalent for Afluria Quadrivalent (IIV4) and at https://www.fda.gov/vaccines-blood-biologics/vaccines/ fluzone-quadrivalent for Fluzone Quadrivalent (IIV4).

\section{Primary Changes and Updates in the Recommendations}

Routine annual influenza vaccination of all persons aged $\geq 6$ months who do not have contraindications continues to be recommended. No preferential recommendation is made for one influenza vaccine product over another for persons for whom more than one licensed, recommended, and appropriate product is available. Updated information in this report includes the following:

1. 2019-20 U.S. trivalent influenza vaccines will contain hemagglutinin (HA) derived from an A/Brisbane/02/2018 (H1N1)pdm09-like virus, an A/Kansas/14/2017 (H3N2)-like virus, and a B/Colorado/06/2017-like virus (Victoria lineage). Quadrivalent influenza vaccines will contain HA derived from these three viruses and from an additional influenza $B$ vaccine virus, a B/Phuket/3073/2013-like virus (Yamagata lineage). This composition includes updates in the influenza $A(\mathrm{H} 1 \mathrm{~N} 1) p d m 09$ and influenza $A(\mathrm{H} 3 \mathrm{~N} 2)$ components of the vaccine.

2. Two recent regulatory actions are described:

- In October 2018, FDA approved an expanded age indication for Afluria Quadrivalent (IIV4). Previously licensed for persons aged $\geq 5$ years, Afluria Quadrivalent (IIV4) is now licensed for persons aged $\geq 6$ months. The dose volume is $0.25 \mathrm{~mL}$ per dose (containing $7.5 \mu \mathrm{g}$ of HA per vaccine virus) for children aged 6 through 35 months and $0.5 \mathrm{~mL}$ per dose (containing $15 \mu \mathrm{g}$ of HA per vaccine virus) for all persons aged $\geq 36$ months ( $\geq 3$ years).

- In January 2019, FDA approved a change in dose volume for Fluzone Quadrivalent (IIV4). Previously, the dose volume for children aged 6 through 35 months was $0.25 \mathrm{~mL}$ (containing $7.5 \mu \mathrm{g}$ of HA per vaccine virus). Children aged 6 through 35 months who receive Fluzone Quadrivalent may now receive either $0.25 \mathrm{~mL}$ (containing $7.5 \mu \mathrm{g}$ of HA per vaccine virus) or $0.5 \mathrm{~mL}$ (containing $15 \mu \mathrm{g}$ of HA per vaccine virus) per dose. Children aged $\geq 36$ months ( $\geq 3$ years) and adults should receive $0.5 \mathrm{~mL}$ per dose. 


\section{Recommendations for the Use of Influenza Vaccines, 2019-20}

\section{Groups Recommended for Vaccination}

Routine annual influenza vaccination is recommended for all persons aged $\geq 6$ months who do not have contraindications. Recommendations regarding timing of vaccination, considerations for specific populations, the use of specific vaccines, and contraindications and precautions are summarized in the sections that follow.

\section{Timing of Vaccination}

Balancing considerations regarding the unpredictability of timing of onset of the influenza season and concerns that vaccine-induced immunity might wane over the course of a season, it is recommended that vaccination should be offered by the end of October. Children aged 6 months through 8 years who require 2 doses (see Children Aged 6 Months Through 8 Years) should receive their first dose as soon as possible after the vaccine becomes available to allow the second dose (which must be administered $\geq 4$ weeks later) to be received by the end of October. For those requiring only 1 dose for the season, early vaccination (i.e., in July and August) is likely to be associated with suboptimal immunity before the end of the influenza season, particularly among older adults. Community vaccination programs should balance maximizing likelihood of persistence of vaccine-induced protection through the season with avoiding missed opportunities to vaccinate or vaccinating after onset of influenza circulation occurs. Efforts should be structured to optimize vaccination coverage before influenza activity in the community begins. No recommendation is made for revaccination later in the season of persons who have already been fully vaccinated (i.e., providing a booster dose). Vaccination should continue to be offered as long as influenza viruses are circulating and unexpired vaccine is available. To avoid missed opportunities for vaccination, providers should offer vaccination during routine health care visits and hospitalizations.

Optimally, vaccination should occur before onset of influenza activity in the community. However, because timing of the onset, peak, and decline of influenza activity varies, the ideal time to start vaccinating cannot be predicted each season. Moreover, more than one outbreak might occur in a given community in a single year. In the United States, localized outbreaks that indicate the start of seasonal influenza activity can occur as early as October. However, in $75 \%$ of 36 influenza seasons from 1982-83 through 2017-18, peak influenza activity (which often is close to the midpoint of influenza activity for the season) has not occurred until January or later, and in $58 \%$ of seasons, the peak was in February or later (16). Activity most commonly peaked in February in 15 (42\%) of these seasons (16).

Several observational studies (17-25) and a post hoc analysis from a randomized controlled trial (26) have reported decreases in vaccine effectiveness (VE) within a single influenza season, with increasing time postvaccination. Waning effects have not been observed consistently across age groups, virus subtypes, and seasons, and observed decreases in protection could be at least in part attributable to bias, unmeasured confounding, or the late-season emergence of antigenic drift variants that are less well-matched to the vaccine strains. Some studies suggest this occurs to a greater degree with influenza $\mathrm{A}(\mathrm{H} 3 \mathrm{~N} 2)$ viruses than with influenza $A(H 1 N 1)$ or influenza $B$ viruses $(22,24)$. This effect also might vary with recipient age; in some studies, waning was more pronounced among older adults $(17,19)$ and younger children (19). Rates of decline in VE have also varied. A multiseason (2011-12 through 2014-15) analysis from the U.S. Influenza Vaccine Effectiveness (U.S. Flu VE) Network found that VE decreased by approximately $7 \%$ per month for influenza $\mathrm{A}(\mathrm{H} 3 \mathrm{~N} 2)$ and influenza $\mathrm{B}$ and $6 \%-11 \%$ per month for influenza $\mathrm{A}(\mathrm{H} 1 \mathrm{~N} 1)$ pdm09 (21). VE remained greater than zero for at least 5 to 6 months after vaccination. An analysis of the 2010-11 through 2013-14 seasons noted protection estimates ranging from $54 \%$ to $67 \%$ during days 0 through 180 postvaccination; estimated VE was not statistically significant during the period between days 181 and 365 (20). A third multiseason analysis (2010-11 through 2014-15) conducted in Europe noted a decline in VE to $0 \%$ at 111 days postvaccination for influenza $\mathrm{A}(\mathrm{H} 3 \mathrm{~N} 2)$ viruses. $\mathrm{VE}$ against influenza $\mathrm{B}$ viruses decreased more slowly, and VE against influenza $\mathrm{A}(\mathrm{H} 1 \mathrm{~N} 1)$ viruses remained roughly stable at $50 \%-55 \%$ through the influenza season (24).

Variable data concerning presence and rate of waning immunity after influenza vaccination, coupled with the unpredictable timing of the influenza season each year, prevent determination of an optimal time to vaccinate. Programmatic issues are also a consideration; although delaying vaccination might result in greater immunity later in the season, deferral also might result in missed opportunities to vaccinate, as well as difficulties in vaccinating a population within a more constrained time period. The potential contributions of these factors among persons aged $\geq 65$ years have been assessed using a simulated mathematical model examining various scenarios of vaccination timing, timing of onset of the influenza season, rate of waning, and vaccine effectiveness (27). In this model, assuming a historical average timing of onset of the influenza season, delaying vaccination until October resulted in more hospitalizations if $>11 \%$ of persons aged $\geq 65$ years who would have been vaccinated in August or September failed to get 
vaccinated. However, these predictions varied considerably with assumed timing of season onset, rate of waning immunity, and vaccine effectiveness.

Vaccination efforts should continue throughout the season because the duration of the influenza season varies, and influenza activity might not occur in certain communities until February or March. Providers should offer influenza vaccine routinely, and organized vaccination campaigns should continue throughout the influenza season, including after influenza activity has begun in the community. Although vaccination by the end of October is recommended, vaccine administered in December or later, even if influenza activity has already begun, might be beneficial in the majority of influenza seasons.

\section{Guidance for Use in Specific Populations and Situations}

\section{Populations at Higher Risk for Medical Complications Attributable to Severe Influenza}

All persons aged $\geq 6$ months who do not have contraindications should be vaccinated annually. However, vaccination to prevent influenza is particularly important for persons who are at increased risk for severe illness and complications from influenza and for influenza-related outpatient, emergency department, or hospital visits. When vaccine supply is limited, vaccination efforts should focus on delivering vaccination to persons at higher risk for medical complications attributable to severe influenza who do not have contraindications. These persons include (no hierarchy is implied by order of listing):

- All children aged 6 through 59 months;

- All persons aged $\geq 50$ years;

- Adults and children who have chronic pulmonary (including asthma), cardiovascular (excluding isolated hypertension), renal, hepatic, neurologic, hematologic, or metabolic disorders (including diabetes mellitus);

- Persons who are immunocompromised due to any cause (including but not limited to immunosuppression caused by medications or HIV infection);

- Women who are or will be pregnant during the influenza season;

- Children and adolescents (aged 6 months through 18 years) who are receiving aspirin- or salicylate-containing medications and who might be at risk for experiencing Reye syndrome after influenza virus infection;

- Residents of nursing homes and other long-term care facilities;

- American Indians/Alaska Natives; and
- Persons who are extremely obese (body mass index $\geq 40$ for adults).

An IIV or RIV4 (as appropriate for the recipient's age) is suitable for persons in all risk groups. LAIV4 is not recommended for some populations, including some of these listed groups. Contraindications and precautions to the use of LAIV4 are noted (Table 2).

\section{Persons Who Live with or Care for Persons at Higher Risk for Influenza-Related Complications}

All persons aged $\geq 6$ months without contraindications should be vaccinated annually; however, in addition to persons at higher risk for medical complications attributable to severe influenza, emphasis also should be placed on vaccination of persons who live with or care for those who are at increased risk. When vaccine supply is limited, vaccination efforts should focus on delivering vaccination to persons at higher risk for influenza-related complications, as well as persons who live with or care for such persons, including the following:

- Health care personnel, including all paid and unpaid persons working in health-care settings who have the potential for exposure to patients and/or to infectious materials. These personnel might include (but are not limited to) physicians, nurses, nursing assistants, nurse practitioners, physician assistants, therapists, technicians, emergency medical service personnel, dental personnel, pharmacists, laboratory personnel, autopsy personnel, students and trainees, contractual staff, and other persons not directly involved in patient care but who can potentially be exposed to infectious agents (e.g., clerical, dietary, housekeeping, laundry, security, maintenance, administrative, billing, and volunteers). ACIP guidance for immunization of health care personnel has been published previously (28);

- Household contacts (including children) and caregivers of children aged $\leq 59$ months (i.e., aged $<5$ years) and adults aged $\geq 50$ years, particularly contacts of children aged $<6$ months; and

- Household contacts (including children) and caregivers of persons with medical conditions that put them at higher risk for severe complications from influenza.

Health care personnel and persons who are contacts of persons in these groups (with the exception of those of severely immunocompromised persons who require a protected environment) may receive any influenza vaccine that is otherwise indicated. Persons who care for severely immunocompromised persons requiring a protected environment should receive either IIV or RIV4. ACIP and the Healthcare Infection Control Practices Advisory Committee (HICPAC) have previously recommended that health care 
personnel who receive LAIV should avoid providing care for severely immunosuppressed patients requiring a protected environment for 7 days after vaccination and that hospital visitors who have received LAIV should avoid contact with such persons for 7 days after vaccination (29). However, such persons need not be restricted from visiting less severely immunosuppressed patients.

\section{Children Aged 6 Months Through 8 Years}

Vaccines and dose volumes for children aged 6 through 35 months: Children aged 6 through 35 months may receive one of four IIV4s licensed for this age group. The appropriate dose volumes for these vaccines differ for this age group (Table 3 ). For these vaccines, children aged 6 through 35 months may receive:

- $0.25 \mathrm{~mL}$ per dose of Afluria Quadrivalent (containing $7.5 \mu \mathrm{g}$ of HA per vaccine virus); or

- $0.5 \mathrm{~mL}$ per dose of Fluarix Quadrivalent (containing $15 \mu \mathrm{g}$ of HA per vaccine virus); or

- $0.5 \mathrm{~mL}$ per dose of FluLaval Quadrivalent (containing $15 \mu \mathrm{g}$ of HA per vaccine virus); or

- Either $0.25 \mathrm{~mL}$ per dose (containing $7.5 \mu \mathrm{g}$ of HA per vaccine virus) or $0.5 \mathrm{~mL}$ per dose (containing $15 \mu \mathrm{g}$ of HA per vaccine virus) of Fluzone Quadrivalent.

Alternatively, healthy children aged $\geq 2$ years may receive LAIV4, $0.2 \mathrm{~mL}$ intranasally $(0.1 \mathrm{~mL}$ in each nostril) (see Contraindications and Precautions for the Use of LAIV4; Table 2). LAIV4 is not licensed for children aged $<2$ years.

Care should be taken to administer an age-appropriate vaccine at the appropriate volume for each dose. For IIV4, the needed volume may be administered from a prefilled syringe containing the appropriate volume (as supplied by the manufacturer), a single-dose vial, or a multidose vial. However, if a $0.5-\mathrm{mL}$ single-dose vial is used for a $0.25-\mathrm{mL}$ dose for a child aged 6 through 35 months, only half the volume should be administered, and the other half should be discarded. Fluzone Quadrivalent may be given to children in this age group as either $0.25 \mathrm{~mL}$ per dose or $0.5 \mathrm{~mL}$ per dose. No preference is expressed for one or the other dose volume.

For several seasons before November 2016, the only IIV formulations licensed for children aged 6 through 35 months were the $0.25-\mathrm{mL}$ dose formulations of Fluzone and Fluzone Quadrivalent (containing $7.5 \mu \mathrm{g}$ of HA per vaccine virus). The recommendation for use of a reduced dose volume for children in this age group (half the dose recommended for persons aged $\geq 3$ years) was based on increased reactogenicity noted among children (particularly younger children) after influenza vaccination, primarily observed with wholevirus inactivated vaccines (30-34). Vaccines more similar to currently available split-virus inactivated products have
TABLE 3. Dose volumes for inactivated influenza vaccines licensed for children aged 6 through 35 months*- United States, 2019-20 influenza season

\begin{tabular}{lc}
\hline Trade name (Manufacturer) & $\begin{array}{c}\text { Dose volume for children } \\
\text { aged } 6 \text { through } 35 \text { mos } \\
\text { ( } \mu \text { g HA per vaccine virus) }\end{array}$ \\
\hline Afluria Quadrivalent (Seqirus) & $0.25 \mathrm{~mL}(7.5 \mu \mathrm{g})$ \\
Fluarix Quadrivalent (GlaxoSmithKline) & $0.5 \mathrm{~mL}(15 \mu \mathrm{g})$ \\
FluLaval Quadrivalent (GlaxoSmithKline) $^{\text {Fluzone Quadrivalent }{ }^{\dagger} \text { (Sanofi Pasteur) }}$ & $0.5 \mathrm{~mL}(15 \mu \mathrm{g})$ \\
& $0.25 \mathrm{~mL}(7.5 \mu \mathrm{g})$ \\
& $0.5 \mathrm{~mL}(15 \mu \mathrm{g})$ \\
\hline
\end{tabular}

Abbreviation: $\mathrm{HA}=$ hemagglutinin.

* For persons aged $\geq 36$ months ( $\geq 3$ years), the dose volume is $0.5 \mathrm{~mL}$ for all inactivated influenza vaccines.

† Fluzone Quadrivalent may be administered as either $0.25 \mathrm{~mL}$ or $0.5 \mathrm{~mL}$ per dose (with no preference expressed for one volume over the other) for children aged 6 through 35 months.

demonstrated less reactogenicity (34). Since November 2016, three IIV4s (Fluarix Quadrivalent, FluLaval Quadrivalent, and Fluzone Quadrivalent) have been approved for administration to this age group at the higher $0.5-\mathrm{mL}$ dose (containing $15 \mu \mathrm{g}$ of HA per vaccine virus) on the basis of studies demonstrating acceptable safety profiles (35-37).

Number of doses for children aged 6 months through 8 years: Children aged 6 months through 8 years require 2 doses of influenza vaccine administered a minimum of 4 weeks apart during their first season of vaccination for optimal protection (38-41). Determination of the number of doses needed is based on 1) the child's age at the time of the first dose of 2019-20 influenza vaccine and 2) the number of doses of influenza vaccine received in previous influenza seasons:

- Adults and children aged $\geq 9$ years need only 1 dose of influenza vaccine for the 2019-20 season.

- For those aged 6 months through 8 years, the number of doses of influenza vaccine needed for the 2019-20 influenza season is determined as follows (Figure):

- Those who have previously received $\geq 2$ total doses of trivalent or quadrivalent influenza vaccine $\geq 4$ weeks apart before July 1, 2019, require only 1 dose for 2019-20. The 2 previous doses of influenza vaccine do not need to have been administered in the same season or consecutive seasons.

- Those who have not previously received $\geq 2$ doses of trivalent or quadrivalent influenza vaccine $\geq 4$ weeks apart before July 1, 2019, or whose previous influenza vaccination history is unknown, require 2 doses for 2019-20. The interval between the 2 doses should be $\geq 4$ weeks. Two doses are recommended even if the child turns age 9 years between receipt of dose 1 and dose 2 . 
FIGURE. Influenza vaccine dosing algorithm for children aged 6 months through 8 years* - Advisory Committee on Immunization Practices, United States, 2019-20 influenza season

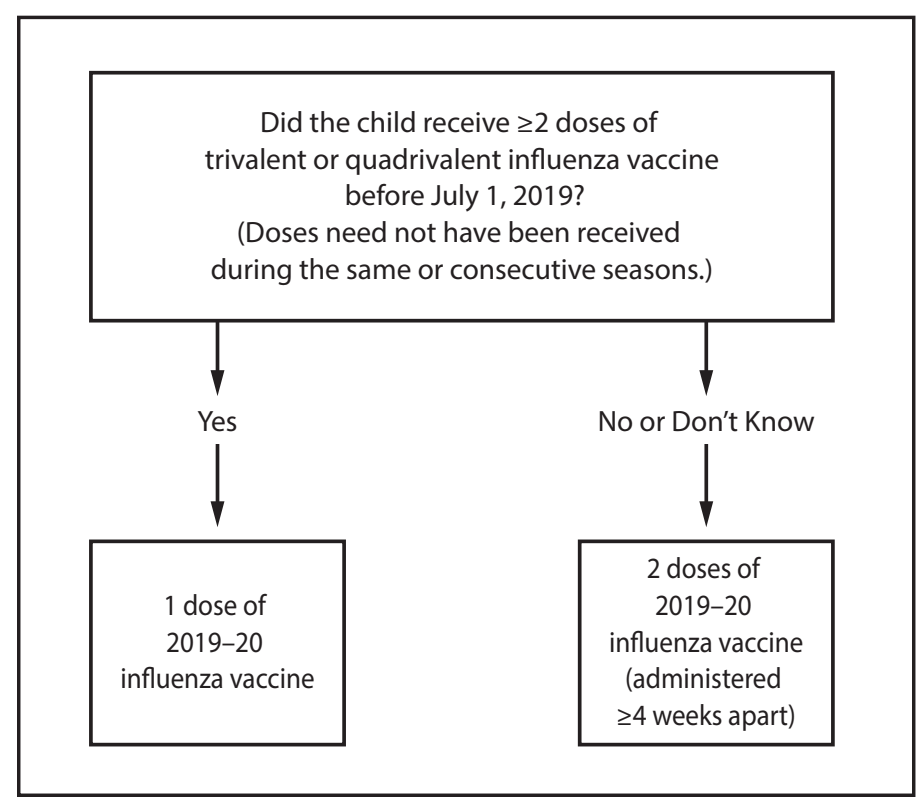

* For children aged 8 years who require 2 doses of vaccine, both doses should be administered even if the child turns age 9 years between receipt of dose 1 and dose 2 .

\section{Pregnant Women}

Pregnant and postpartum women have been observed to be at higher risk for severe illness and complications from influenza, particularly during the second and third trimesters. ACIP and the American College of Obstetricians and Gynecologists $(42,43)$ recommend that all women who are pregnant or who might be pregnant or postpartum during the influenza season receive influenza vaccine. Any licensed, recommended, and age-appropriate IIV or RIV4 may be used. LAIV4 should not be used during pregnancy. Influenza vaccine can be administered at any time during pregnancy, before and during the influenza season.

Although there is substantial experience with the use of IIVs during pregnancy, data specifically reflecting administration of influenza vaccines during the first trimester are relatively limited (see Safety of Influenza Vaccines-Pregnant Women and Neonates in the supplementary Background Document). Most studies have not noted an association between influenza vaccination and adverse pregnancy outcomes, including spontaneous abortion (44-54). One observational Vaccine Safety Datalink (VSD) study conducted during the 2010-11 and 2011-12 seasons noted an association between receipt of IIV containing H1N1pdm09 and risk for spontaneous abortion (miscarriage) in the 28 days after IIV, when an H1N1pdm09-containing vaccine had also been received the previous season (55). However, in a larger VSD follow-up study,
IIV was not associated with an increased risk for spontaneous abortion during the 2012-13, 2013-14, and 2014-15 seasons, regardless of previous season vaccination (56).

There is substantially less experience with more recently licensed IIV products (e.g., quadrivalent and cell culture-based vaccines) during pregnancy as compared with previously available products. For RIV (available as RIV3 from 2013-14 through 2017-18 and as RIV4 since 2017-18), data are limited to reports of pregnancies occurring incidentally during clinical trials, Vaccine Adverse Event Reporting System (VAERS) reports, and pregnancy registries. Pregnancy registries and surveillance studies exist for some products; information can be found in package inserts at https://www.fda.gov/vaccinesblood-biologics/vaccines/influenza-virus-vaccine-trivalenttypes-and-b for trivalent vaccines, and at https://www.fda. gov/vaccines-blood-biologics/vaccines/influenza-virus-vaccinequadrivalent-types-and-types-b for quadrivalent vaccines.

\section{Older Adults}

Because of the vulnerability of older adults to severe influenza illness, hospitalization, and death, efficacy and effectiveness of influenza vaccines in this population is an area of active research (see Immunogenicity, Efficacy, and Effectiveness of Influenza Vaccines: HD-IIV3, aIIV3, and RIV4 for Older Adults in the Background Document). Recent comparative studies of vaccine efficacy/effectiveness against laboratoryconfirmed influenza outcomes among older adults have focused on HD-IIV3 (Fluzone High-Dose) (57-60), RIV4 (Flublok Quadrivalent) (61), and aIIV3 (Fluad) (62) (see Table in Background Document; https://www.cdc.gov/flu/ professionals/acip/2019-2020/acip-table.htm). These studies have evaluated each of these three vaccines compared with standard-dose, unadjuvanted IIV. To date, HD-IIV3 has been the most extensively studied in this regard, and evidence has accumulated for its superior efficacy and effectiveness compared with SD-IIV3 in this population. Data from studies comparing the efficacy or effectiveness of HD-IIV3, aIIV3, and RIV4 directly with one another against laboratory-confirmed influenza outcomes among older adults are limited, which prevents recommending one of these three vaccines over another for this population. In comparative safety studies, some injection site and systemic reactions were observed more frequently in older persons vaccinated with HD-IIV3 and aIIV3 compared with unadjuvanted SD-IIV3 $(63,64)$.

Fluzone High-Dose (HD-IIV3) met prespecified criteria for superior efficacy against laboratory-confirmed influenza compared with that of Fluzone SD-IIV3 in a randomized trial conducted over two seasons (2011-12 and 2012-13) among 31,989 persons aged $\geq 65$ years and might provide better protection than SD-IIV3 for this age group $(58,65,66)$. For 
the primary outcome (prevention of laboratory-confirmed influenza caused by any viral type or subtype and associated with protocol-defined influenza-like illness [ILI]), relative efficacy of Fluzone HD-IIV3 compared with Fluzone SD-IIV3 was 24.2\% (95\% confidence interval [CI]: 9.7\%-36.5\%). These findings are further supported by results from retrospective studies of Centers for Medicare and Medicaid Services (CMS) and Veterans Administration data, as well as a cluster-randomized trial of HD-IIV3 compared with SD-IIV among older adults in nursing homes (67-71). A meta-analysis reported that HD-IIV3 provided better protection than SD-IIV3 against ILI (relative VE $=19.5 \%$; 95\% CI: 8.6\%-29.0\%); all-cause hospitalizations (relative VE $=9.1 \%$; 95\% CI: 2.4-15.3); and hospitalizations due to influenza (relative $\mathrm{VE}=17.8 \%$; 95\% CI: 8.1-26.5), pneumonia (relative $\mathrm{VE}=24.3 \%$; 95\% CI: 13.9-33.4), and cardiorespiratory events (relative VE $=18.2 \%$; 95\% CI: 6.8-28.1) (72).

In an exploratory analysis of data from a single-season (2014-15) randomized trial conducted among 8,604 adults aged $\geq 50$ years, Flublok Quadrivalent (RIV4) was more efficacious than SD-IIV4 $(61,73)$; however, no claim of superiority was approved for the package insert (73). For the primary outcome (protocol-defined ILI, caused by any influenza virus type or subtype, confirmed by reverse transcription polymerase chain reaction), the relative $\mathrm{VE}$ of RIV4 compared with SD-IIV4 was 30\% (95\% CI: 10-47). When restricted to persons aged $\geq 65$ years, the relative $\mathrm{VE}$ of RIV4 was 17\% (95\% CI: -20\%-43\%).

No data are available concerning efficacy of aIIV3 compared with nonadjuvanted IIV3 against laboratory-confirmed influenza outcomes from a randomized trial in older adults. Fluad (aIIV3) was more effective against laboratory-confirmed influenza than unadjuvanted SD-IIV3 among adults aged $\geq 65$ years ( $\mathrm{N}=227,165$ of whom received aIIV3 and 62 SD-IIV3) in an analysis from a small single-season (2011-12) observational study (62). The relative effectiveness of aIIV3 compared with unadjuvanted SD-IIV3 was 63\% (95\% CI: 4-86). Fluad was associated with reduced risk for hospitalization for pneumonia and influenza diagnoses (74) and pneumonia, cerebrovascular, or cardiovascular diagnoses relative to unadjuvanted IIV3 in retrospective studies of medical record data (75).

Additional data concerning these vaccines from studies examining immunogenicity and non-laboratory-confirmed influenza outcomes are discussed in the Background Document. ACIP will continue to review data on the efficacy and effectiveness of these vaccines as more information emerges. No preference is expressed for any one vaccine type. Vaccination should not be delayed if a specific product is not readily available. For persons aged $\geq 65$ years, any ageappropriate IIV formulation (standard dose or high dose, trivalent or quadrivalent, unadjuvanted or adjuvanted) or RIV4 are acceptable options

\section{Immunocompromised Persons}

Immunocompromised states comprise a heterogeneous range of conditions with varying risk for severe infections. In many instances, limited data are available regarding the use of influenza vaccines in the setting of specific immunocompromised states. Persons with immunocompromising conditions should receive an age-appropriate IIV or RIV4. ACIP recommends that LAIV4 not be used for these groups because of the uncertain but biologically plausible risk for disease attributable to the vaccine virus (76).

Immune response to influenza vaccines might be blunted in persons with some conditions, such as persons with congenital immune deficiencies, persons receiving cancer chemotherapy, and persons receiving immunosuppressive medications. Timing of vaccination might be a consideration (e.g., vaccinating during some period either before or after an immunocompromising intervention). The Infectious Diseases Society of America (IDSA) has published detailed guidance for the selection and timing of vaccines for persons with specific immunocompromising conditions, including congenital immune disorders, stem cell and solid organ transplant, anatomic and functional asplenia, and therapeutic drug-induced immunosuppression, as well as for persons with cochlear implants or other conditions leading to persistent cerebrospinal fluid-oropharyngeal communication (77). Because of the paucity of safety data for LAIV4 in most of these populations and the availability of alternative vaccines, IIV or RIV4 should be used instead of LAIV4 for persons affected by these conditions. ACIP will continue to review accumulating data on use of influenza vaccines in these contexts.

\section{Persons with a History of Guillain-Barré Syndrome After Influenza Vaccination}

A history of Guillain-Barré Syndrome (GBS) within 6 weeks of a previous dose of any type of influenza vaccine is considered a precaution to vaccination (Table 2). Persons who are not at higher risk for severe influenza complications (see Populations at Higher Risk for Medical Complications Attributable to Severe Influenza) and who are known to have experienced GBS within 6 weeks of a previous influenza vaccination generally should not be vaccinated. As an alternative to vaccination, physicians might consider using influenza antiviral chemoprophylaxis for these persons (78). However, the benefits of influenza vaccination might outweigh the risks for certain persons who have a history of GBS within 6 weeks after receipt of influenza vaccine and who also are at higher risk for severe complications from influenza. 


\section{Persons with a History of Egg Allergy}

As is the case for all vaccines, influenza vaccines contain various different components that might cause allergic and anaphylactic reactions. Not all such reactions are related to egg proteins; however, the possibility of reactions to influenza vaccines in egg-allergic persons might be of concern to these persons and vaccine providers. Currently available influenza vaccines, with the exceptions of RIV4 (Flublok Quadrivalent, licensed for ages $\geq 18$ years) and ccIIV4 (Flucelvax Quadrivalent, licensed for ages $\geq 4$ years), are prepared by propagation of virus in embryonated eggs and might contain trace amounts of egg proteins, such as ovalbumin.

Severe allergic reactions to vaccines, although rare, can occur at any time, even in the absence of a history of previous allergic reaction. Therefore, all vaccine providers should be familiar with the office emergency plan and be certified in cardiopulmonary resuscitation (76). For persons who report a history of egg allergy, ACIP recommends the following:

- Persons with a history of egg allergy who have experienced only urticaria (hives) after exposure to egg should receive influenza vaccine. Any licensed, recommended influenza vaccine (i.e., any IIV, RIV4, or LAIV4) that is otherwise appropriate for the recipient's age and health status may be used.

- Persons who report having had reactions to egg involving symptoms other than urticaria (e.g., angioedema or swelling, respiratory distress, lightheadedness, or recurrent vomiting) or who required epinephrine or another emergency medical intervention may similarly receive any licensed, recommended influenza vaccine (i.e., any IIV, RIV4, or LAIV4) that is otherwise appropriate for their age and health status. The selected vaccine should be administered in an inpatient or outpatient medical setting (including, but not necessarily limited to, hospitals, clinics, health departments, and physician offices). Vaccine administration should be supervised by a health care provider who is able to recognize and manage severe allergic reactions.

- A previous severe allergic reaction to influenza vaccine, regardless of the component suspected of being responsible for the reaction, is a contraindication to future receipt of the vaccine.

No postvaccination observation period is recommended specifically for egg-allergic persons. However, ACIP recommends that vaccine providers consider observing patients (seated or supine) for 15 minutes after administration of any vaccine to decrease the risk for injury should syncope occur (76).

Persons who are able to eat lightly cooked egg (e.g., scrambled egg) without a reaction are unlikely to be allergic.
Egg-allergic persons might tolerate egg in baked products (e.g., bread or cake). Tolerance to egg-containing foods does not exclude the possibility of egg allergy. Egg allergy can be confirmed by a consistent medical history of adverse reactions to eggs and egg-containing foods, plus skin or blood testing for immunoglobulin E directed against egg proteins (79).

Occasional cases of anaphylaxis after administration of influenza vaccines in egg-allergic persons have been reported to VAERS $(80,81)$. ACIP will continue to review available data regarding anaphylaxis cases after receipt of influenza vaccines.

\section{Vaccination Issues for Travelers}

Travelers who want to reduce the risk for influenza infection should consider influenza vaccination, preferably at least 2 weeks before departure. In particular, persons who live in the United States and are at higher risk for complications of influenza and who were not vaccinated with influenza vaccine during the previous Northern Hemisphere fall or winter should consider receiving influenza vaccine before departure if they plan to travel to the tropics, with organized tourist groups or on cruise ships, or to the Southern Hemisphere during the Southern Hemisphere influenza season (April-September).

Persons at higher risk who received the previous season's vaccine before travel should consult with their health care provider to discuss the risk for influenza or other travel-related diseases before embarking on travel during the summer. All persons (regardless of risk status) vaccinated before travel should receive the current vaccine the following fall or winter.

In temperate climate regions of the Northern and Southern hemispheres, influenza activity is seasonal, occurring approximately from October through May in the Northern Hemisphere and April through September in the Southern Hemisphere. In the tropics, influenza might occur throughout the year. Travelers can be exposed to influenza when traveling to an area where influenza is circulating or when traveling as part of large tourist groups (e.g., on cruise ships) that include persons from areas of the world in which influenza viruses are circulating (82-85).

Influenza vaccine formulated for the Southern Hemisphere might differ in viral composition from the Northern Hemisphere vaccine. For persons traveling to the Southern Hemisphere during the Southern Hemisphere influenza season, receipt of a current U.S.-licensed Southern Hemisphere formulation influenza vaccine before departure might be reasonable but might not be feasible because of limited access to or unavailability of this vaccine in the United States. With the exception of the Southern Hemisphere formulation of Fluzone Quadrivalent (IIV4), Southern Hemisphere formulation seasonal influenza vaccines are not licensed in the United States and generally are not commercially available in 
the United States. More information on influenza vaccines and travel is available at https://wwwnc.cdc.gov/travel/diseases/ influenza-seasonal-zoonotic-and-pandemic.

\section{Use of Influenza Antiviral Medications}

Administration of IIV or RIV4 to persons receiving influenza antiviral medications for treatment or chemoprophylaxis is acceptable. However, influenza antiviral medications might reduce the effectiveness of LAIV4 if given within the interval from 48 hours before to 14 days after administration of LAIV4 (86). Persons who receive influenza antiviral medications during this period surrounding receipt of LAIV4 can be revaccinated with another appropriate influenza vaccine (e.g., IIV or RIV4).

\section{Administration of Influenza Vaccines with Other Vaccines}

IIVs and RIV4 may be administered concomitantly or sequentially with other inactivated vaccines or live vaccines. Injectable vaccines that are given concomitantly should be administered at separate anatomical sites. LAIV4 may be administered simultaneously with other live or inactivated vaccines. However, after administration of a live vaccine (such as LAIV4), at least 4 weeks should pass before another live vaccine is administered (76).

Relatively limited data are available on the concomitant administration of influenza vaccines with other vaccines. Studies of live attenuated zoster vaccine and IIV3 (87) or IIV4 (88) among persons aged $\geq 50$ years noted similar antibody responses whether the two vaccines were administered concomitantly or 4 weeks apart. In some studies, reduced responses have been noted to 13 -valent pneumococcal conjugate vaccine (PCV13) $(89,90)$, tetanus antigens (91), and pertussis antigens (91) when co-administered with IIV3 to adults; in most instances the clinical significance of this is uncertain. Simultaneous administration of IIV 4 and 23-valent pneumococcal polysaccharide vaccine (PPSV23) to persons aged $\geq 65$ years was associated with lower seroprotection rates to one influenza B antigen at 4-6 weeks postvaccination as compared with sequential administration 2 weeks apart; seroprotection was not significantly different between the two groups for any of the four influenza antigens at 6 months postvaccination (92). Reassuring safety profiles have been noted for simultaneous administration of IIVs with live attenuated zoster vaccine $(87,88), \operatorname{PCV} 13(89,90)$ PPSV23 $(92,93)$ and tetanus toxoid, reduced diphtheria toxoid, and acellular pertussis (Tdap) vaccine among adults (91) and of Tdap among pregnant women (94). Although increased prevalence of injection site or systemic adverse reactions has been noted with concurrent administration in some of these studies, these symptoms have generally been reported to be mild or moderate.

Among children aged 6 through 23 months, co-administration of IIV and PCV13 was associated with increased risk for fever on the day of vaccination and the day after (i.e., days $0-1$ postvaccination) in a study conducted during the 2011-12 season (95). Increased risk for febrile seizures in this age group has been noted within days $0-1$ after co-administration of IIV with PCV7, PCV13, or diphtheria and tetanus toxoids and acellular pertussis (DTaP) vaccines during the 2006-07 through 2010-11 seasons (96) and with PCV13 during the 2014-15 season (97). Although of concern to parents, most febrile seizures are brief and have a good prognosis (98). After considering the risks and benefits, no changes in the recommendations for administration of these vaccines were made, and these vaccines can be given concomitantly. Surveillance of febrile seizures is ongoing through VAERS, and the VSD annual influenza safety surveillance includes monitoring for seizures after vaccinations.

Studies of concomitant administration of LAIV with other vaccines are limited. Concurrent administration of LAIV3 with MMR and varicella vaccine to children was not associated with diminished immunogenicity to antigens in any of the vaccines in one study (99); diminished response to rubella was observed in another study examining co-administration of LAIV3 and MMR (100). No safety concerns were noted in these studies.

In recent years, several vaccines containing novel, nonaluminum adjuvants have been licensed for use in the United States. These include AS01 $1_{B}$ (in Shingrix, recombinant zoster subunit vaccine); MF59 (in Fluad, aIIV3); and cytosine phosphoguanine oligodeoxynucleotide (in Heplisav-B, recombinant hepatitis $B$ surface antigen vaccine). Data are limited regarding co-administration of these vaccines with other adjuvanted or unadjuvanted vaccines. Co-administration of Shingrix with unadjuvanted IIV4 has been studied; no evidence of decreased immunogenicity or safety concerns were noted (101). The immunogenicity and safety of simultaneous or sequential administration of two novel adjuvantcontaining vaccines has not been evaluated, and the ideal interval between such vaccines when given sequentially is not known. In the study of Shingrix and IIV4 (101), most reactogenicity symptoms resolved within 4 days. Because of the limited data on the safety of simultaneous administration of two or more vaccines containing novel adjuvants and the availability of nonadjuvanted influenza vaccine options, selection of a nonadjuvanted influenza vaccine may be considered in situations in which influenza vaccine and another vaccine containing a novel adjuvant are to be administered concomitantly. However, vaccination should not be delayed if a specific product is not available. As recommended for all 
vaccines, vaccines with novel adjuvants should be administered at separate anatomical sites from other vaccines that are given concomitantly (76).

\section{Influenza Vaccine Composition and Available Products}

\section{Influenza Vaccine Composition for the 2019-20 Season}

All influenza vaccines licensed in the United States will contain components derived from influenza viruses antigenically similar to those recommended by FDA (https:// www.fda.gov/advisory-committees/vaccines-and-relatedbiological-products-advisory-committee/2019-meetingmaterials-vaccines-and-related-biological-products-advisorycommittee). Both trivalent and quadrivalent influenza vaccines will be available in the United States. The 2019-20 U.S. influenza vaccines will contain HA derived from the following:

- an A/Brisbane/02/2018 (H1N1)pdm09-like virus,

- an A/Kansas/14/2017 (H3N2)-like virus, and

- a B/Colorado/06/2017-like virus (Victoria lineage)

The 2019-20 U.S. quadrivalent influenza vaccines will contain HA derived from these three viruses and an additional influenza $\mathrm{B}$ virus $\mathrm{HA}$, a B/Phuket/3073/2013-like virus (Yamagata lineage). Compared with the 2018-19 season, the composition for 2019-20 represents updates in the influenza $\mathrm{A}(\mathrm{H} 1 \mathrm{~N} 1) \mathrm{pdm} 09$ and influenza $\mathrm{A}(\mathrm{H} 3 \mathrm{~N} 2)$ components of the vaccine.

\section{Vaccine Products for the 2019-20 Season}

Various influenza vaccines are licensed for the 2019-20 season (Table 1). For many vaccine recipients, more than one type or brand of vaccine might be appropriate within approved indications and ACIP recommendations. A licensed influenza vaccine that is appropriate for the recipient's age and health status should be used. Specific age indications for licensed influenza vaccines are summarized (Table 1); current prescribing information should be consulted for authoritative, up-to-date information. Contraindications and precautions for the different types of influenza vaccines are summarized (Table 2).

Not all influenza vaccines are likely to be uniformly available in any given practice setting or geographic locality. Vaccination should not be delayed to obtain a specific product when an appropriate one is already available. Within these guidelines and approved indications, when more than one type of vaccine is available and appropriate, no preferential recommendation is made for the use of any one influenza vaccine over another.

Since the publication of the previous season's guidance, two labeling changes have occurred for previously licensed vaccines that will be available for the 2019-20 season. These include a change in the age indication for Afluria Quadrivalent and a change in the dose volume for children aged 6 through 35 months for Fluzone Quadrivalent (see Recent Influenza Vaccine Licensure Changes). New licensures and changes to FDA-approved labeling might occur after publication of this report. As these changes occur, they will be reflected in the online version of Table 1, available at https://www.cdc.gov/flu/protect/vaccine/vaccines.htm.

\section{Dosage, Administration, Contraindications, and Precautions}

\section{Inactivated Influenza Vaccines (IIVs)}

Available products: As in previous seasons, various inactivated influenza vaccines (IIVs) are expected to be available for 2019-20 (Table 1). There are IIVs that are licensed for persons as young as 6 months of age. However, licensed age indications differ for different products. Moreover, for some influenza vaccines, the dosage for children aged 6 through 35 months differs from that for older children and adults (Table 3). Care should be taken to administer the appropriate dose of an age-appropriate product to each recipient.

Standard-dose, unadjuvanted IIVs contain $15 \mu \mathrm{g}$ of HA per vaccine virus in a $0.5-\mathrm{mL}$ dose $(7.5 \mu \mathrm{g}$ of HA per vaccine virus in a $0.25-\mathrm{mL}$ dose). For 2019-20, this category is expected to include five different products (Table 1). All standarddose, unadjuvanted IIVs anticipated to be available for the 2019-20 season will be quadrivalent (IIV4s). Standard-dose, unadjuvanted IIV4s may be egg based or cell culture based. The difference is the substrate in which reference vaccine viruses supplied to the manufacturer are propagated in quantities sufficient to produce the needed number of doses of vaccine. For the 2019-20 season, all IIVs will be egg based, with the exception of Flucelvax Quadrivalent (ccIIV4), for which the influenza vaccine viruses are propagated in Madin-Darby canine kidney cells instead of eggs (102).

High-dose and adjuvanted IIVs will be trivalent. These two vaccines are licensed for persons aged $\geq 65$ years. High-dose inactivated influenza vaccine (Fluzone High-Dose [HD-IIV3]) contains $60 \mu \mathrm{g}$ of HA per vaccine virus (180 $\mu \mathrm{g}$ total) in a $0.5-\mathrm{mL}$ dose (66). Adjuvanted inactivated influenza vaccine (Fluad [aIIV3]) contains $15 \mu \mathrm{g}$ of HA per vaccine virus (45 $\mu \mathrm{g}$ total) in a $0.5-\mathrm{mL}$ dose and also contains MF59 adjuvant (103). Both HD-IIV3 and aIIV3 are egg based. 
Dosage and administration: For children aged 6 through 35 months, four IIV4 products expected to be available for 2019-20 are licensed by FDA: Afluria Quadrivalent, Fluarix Quadrivalent, FluLaval Quadrivalent, and Fluzone Quadrivalent. The approved dose volumes for these vaccines differ for this age group (Table 3). For each of these IIVs, a 0.5 -mL dose contains $15 \mu \mathrm{g}$ of HA per vaccine virus, whereas a $0.25-\mathrm{mL}$ dose contains $7.5 \mu \mathrm{g}$ of HA per vaccine virus. Care should be taken to administer the appropriate dose volume for the particular product. If prefilled syringes are not available, the appropriate volume may be administered from a singledose or multidose vial. If a 0.5 - $\mathrm{mL}$ single-dose vial is used for a $0.25-\mathrm{mL}$ dose for a child aged 6 through 35 months, only half the volume should be administered and the other half should be discarded. Of note, dose volume is distinct from the number of doses. Children in this age group who require 2 doses for 2019-20 (see Children Aged 6 Months through 8 Years; Figure) need 2 separate doses administered $\geq 4$ weeks apart, regardless of the specific IIV used and volume given for each dose.

Children aged 36 months (3 years) through 17 years and adults aged $\geq 18$ years who receive IIVs should receive $0.5 \mathrm{~mL}$ per dose. If a smaller vaccine dose (e.g., $0.25 \mathrm{~mL}$ ) is inadvertently administered to a person aged $\geq 36$ months, an additional $0.25-\mathrm{mL}$ dose should be administered to provide a full dose $(0.5 \mathrm{~mL})$ during the same vaccination visit. If the error is discovered later (after the patient has left the vaccination setting), a full $0.5-\mathrm{mL}$ dose should be administered as soon as the recipient can return. Vaccination with a formulation approved for adult use should be counted as a dose if inadvertently administered to a child.

IIVs are administered intramuscularly (IM). For adults and older children, the deltoid is the preferred site. Infants and younger children should be vaccinated in the anterolateral thigh. Additional specific guidance regarding site selection and needle length for IM injection is provided in the ACIP General Best Practice Guidelines for Immunization (76).

One of the IIVs expected to be available for 2019-20, Afluria Quadrivalent (IIV4), is licensed for IM injection via the PharmaJet Stratis jet injector for persons aged 18 through 64 years (104). Persons in this age group may receive Afluria Quadrivalent via either needle and syringe or this specific jet injection device. Children aged 6 months through 17 years and adults aged $\geq 65$ years should receive this vaccine by needle and syringe only.

Trivalent versus quadrivalent IIVs: Both trivalent and quadrivalent IIVs will be available during the 2019-20 season. Quadrivalent vaccines (IIV4s) contain one virus from each of the two influenza B virus lineages (Yamagata and Victoria), whereas trivalent vaccines (IIV3s) contain one influenza B virus from one lineage (for 2019-20, a Victoria lineage virus). IIV4s are thus designed to provide broader protection against circulating influenza B virus strains. However, no preference is expressed for either quadrivalent or trivalent vaccines.

Contraindications and precautions for the use of IIVs: Manufacturer package inserts and updated $\mathrm{CDC} /$ ACIP guidance should be consulted for information on contraindications and precautions for individual influenza vaccine products. In general, history of a severe allergic reaction to the vaccine or any of its components (including egg) is a labeled contraindication to the receipt of most IIVs (Table 2). However, ACIP makes specific recommendations for the use of influenza vaccine for persons with egg allergy (see Persons with a History of Egg Allergy). Influenza vaccine is not recommended for persons with a history of severe allergic reaction to the vaccine or to components other than egg. Information about vaccine components can be found in the package inserts for each vaccine. Prophylactic use of antiviral agents is an option that can be considered for preventing influenza among those persons who cannot receive vaccine (particularly for those who are at higher risk for medical complications attributable to severe influenza) (78).

Moderate or severe acute illness with or without fever is a general precaution for vaccination (76). A history of GBS within 6 weeks after receipt of a previous dose of influenza vaccine is considered a precaution for the use of influenza vaccines (Table 2 ).

\section{Recombinant Influenza Vaccine (RIV4)}

Available products: One recombinant influenza vaccine, Flublok Quadrivalent (RIV4), is expected to be available during the 2019-20 influenza season. RIV4 is indicated for persons aged $\geq 18$ years. RIV4 is manufactured without the use of influenza viruses or eggs. No preference is expressed for RIV4 versus other influenza vaccines used within specified indications.

Dosage and administration: RIV4 is administered by IM injection. A $0.5-\mathrm{mL}$ dose contains $45 \mu \mathrm{g}$ of HA derived from each vaccine virus (180 $\mu \mathrm{g}$ total).

Contraindications and precautions for the use of RIV4: RIV4 is contraindicated in persons who have had a severe allergic reaction to any component of the vaccine. Moderate or severe acute illness with or without fever is a general precaution for vaccination (76). A history of GBS within 6 weeks after receipt of a previous dose of influenza vaccine is considered a precaution for the use of influenza vaccines (Table 2). RIV4 is not licensed for children aged $<18$ years. 


\section{Live Attenuated Influenza Vaccine (LAIV4)}

Available products: One live attenuated influenza vaccine, FluMist Quadrivalent (LAIV4), is expected to be available during the 2019-20 influenza season. LAIV4 is licensed for persons aged 2 through 49 years.

Dosage and administration: LAIV4 is administered intranasally using the supplied prefilled, single-use sprayer containing $0.2 \mathrm{~mL}$ of vaccine. Approximately $0.1 \mathrm{~mL}$ (i.e., half the total sprayer contents) is sprayed into the first nostril while the recipient is in the upright position. An attached dose-divider clip is removed from the sprayer to permit administration of the second half of the dose into the other nostril. If the recipient sneezes immediately after administration, the dose should not be repeated. However, if nasal congestion is present that might impede delivery of the vaccine to the nasopharyngeal mucosa, deferral of administration should be considered until resolution of the illness, or another appropriate vaccine should be administered instead.

Contraindications and precautions for the use of LAIV4: Per the package insert, LAIV4 is contraindicated for persons with a history of severe allergic reaction to any component of the vaccine or to a previous dose of any influenza vaccine and for children and adolescents receiving concomitant aspirin- or salicylate-containing medications (Table 2). Although LAIV4 is an egg-based vaccine, ACIP makes specific recommendations for the use of influenza vaccines for persons with egg allergy (see Persons with a History of Egg Allergy). In addition to the labeled contraindications (other than allergy to egg), ACIP also recommends that LAIV4 not be administered to the following groups:

- Children aged 2 through 4 years who have received a diagnosis of asthma or whose parents or caregivers report that a health care provider has told them during the past 12 months that their child had wheezing or asthma or whose medical record indicates that a wheezing episode has occurred within the past 12 months;

- Persons who are immunocompromised due to any cause (including but not limited to medications and HIV infection);

- Close contacts and caregivers of severely immunocompromised persons who require a protected environment;

- Pregnant women; and

- Persons who have received influenza antiviral medications within the previous 48 hours.

Moderate or severe acute illness with or without fever is a general precaution for vaccination (76). A history of GBS within 6 weeks after receipt of a previous dose of influenza vaccine is considered a precaution for the use of influenza vaccines (Table 2). Additional precautions specific for LAIV4 include asthma in persons aged $\geq 5$ years and presence of an underlying medical condition (other than the instances previously listed in which LAIV4 should not be used) that might predispose to severe illness with wild-type influenza virus infection (see Populations at Higher Risk for Medical Complications Attributable to Severe Influenza; Table 2).

\section{Recent Influenza Vaccine Licensure Changes}

\section{Afluria Quadrivalent (IIV4)}

In October 2018, FDA approved expansion of the licensed age indications for Afluria (IIV3) and Afluria Quadrivalent (IIV4) from $\geq 5$ years to $\geq 6$ months. Although both Afluria and Afluria Quadrivalent were available during the 2018-19 season, only Afluria Quadrivalent is expected to be available for the 2019-20 season. The dosage for Afluria Quadrivalent is age dependent: the licensed dose volume for children aged 6 through 35 months is $0.25 \mathrm{~mL}$ per dose (containing $7.5 \mu \mathrm{g}$ of HA per vaccine virus), and the dose volume for all persons aged $\geq 36$ months ( $\geq 3$ years) is $0.5 \mathrm{~mL}$ per dose (containing $15 \mu \mathrm{g}$ of HA per vaccine virus) (104).

Expansion of the licensed age indication for Afluria Quadrivalent was based on a randomized, observer-blinded, multicenter immunogenicity and safety study conducted among 2,250 children aged 6 through 59 months who were randomized 3:1 to receive Afluria Quadrivalent or a licensed comparator IIV4 $(105,106)$. In the immunogenicity analysis, Afluria Quadrivalent met prespecified criteria for noninferiority versus the comparator IIV4, with noninferior HA inhibition geometric mean titer ratios and seroconversion rates for all four viruses. The safety profile was generally comparable to that of the comparator IIV4. Overall rates of fever in the 7 days after vaccination were 5.8\% for Afluria Quadrivalent and 8.4\% for the comparator IIV4. No febrile seizures occurred within 7 days following vaccination.

\section{Fluzone Quadrivalent (IIV4)}

In January 2019, FDA approved a change in dose volume for Fluzone Quadrivalent for children aged 6 through 35 months. Previously, the licensed dosage of Fluzone Quadrivalent for children in this age group was $0.25 \mathrm{~mL}$ per dose (containing $7.5 \mu \mathrm{g}$ of HA per vaccine virus). For the 2019-20 season, children aged 6 through 35 months may receive either $0.25 \mathrm{~mL}$ (containing $7.5 \mu \mathrm{g}$ of HA per vaccine virus) or $0.5 \mathrm{~mL}$ (containing $15 \mu \mathrm{g}$ of HA per vaccine virus) per dose. Persons aged $\geq 36$ months ( $\geq 3$ years) should receive the $0.5-\mathrm{mL}$ dose volume (107). 
Licensure of the $0.5-\mathrm{mL}$ dose volume for this age group was based on a randomized, observer-blinded, multicenter safety and immunogenicity study conducted among 1,950 children aged 6 through 35 months, who were randomized 1:1 to receive either $0.25 \mathrm{~mL}$ or $0.5 \mathrm{~mL}$ of Fluzone Quadrivalent $(37,108)$. In the safety analysis, the overall safety profile was similar between the two groups. Rates of fever for the higher dose volume were noninferior to those observed with the lower dose volume. In the immunogenicity analysis, seroconversion rates and HA inhibition geometric mean titer ratios in the group receiving the higher dose volume of Fluzone Quadrivalent met prespecified criteria for noninferiority for all four viruses.

\section{Storage and Handling of Influenza Vaccines}

In all instances, approved manufacturer packaging information should be consulted for authoritative guidance concerning storage and handling of specific influenza vaccines. In general, influenza vaccines should be protected from light and stored at temperatures that are recommended on the package insert. Recommended storage temperatures are generally $2^{\circ} \mathrm{C}$ to $8^{\circ} \mathrm{C}\left(36^{\circ} \mathrm{F}\right.$ to $\left.46^{\circ} \mathrm{F}\right)$, and should be maintained at all times with adequate refrigeration and temperature monitoring. Vaccine that has frozen should be discarded. Specific recommendations for appropriate refrigerators and temperature monitoring equipment can be found in the Vaccine Storage and Handling Toolkit, available at https:// www.cdc.gov/vaccines/hcp/admin/storage/toolkit/index.html.

Vaccines should not be used beyond the expiration date on the label. In addition to the expiration date, multidose vials also might have a Beyond Use Date (BUD), which specifies the number of days the vaccine can be kept once first accessed. Once accessed for the first dose, multidose vials should not be used after the BUD. If no BUD is provided, then the listed expiration date is to be used. Multidose vials should be returned to recommended storage conditions between uses. Package information might also specify a maximum number of doses that should be taken from multidose vials (regardless of remaining volume). Single-dose vials should not be accessed for more than 1 dose. For information on permissible temperature excursions and other departures from recommended storage and handling conditions that are not discussed in the package labeling, contact the manufacturer.

\section{Additional Sources of Information Regarding Influenza and Influenza Vaccines}

\section{Influenza Surveillance, Prevention, and Control}

Updated information regarding influenza surveillance, detection, prevention, and control is available at https://www. cdc.gov/flu. U.S. surveillance data are updated weekly during October through May on FluView (https://www.cdc.gov/flu/ weekly). In addition, periodic updates regarding influenza are published in MMWR (https://www.cdc.gov/mmwr/ index.html). Additional information regarding influenza and influenza vaccines can be obtained from CDC-INFO by calling 1-800-232-4636. State and local health departments should be consulted about availability of influenza vaccines, access to vaccination programs, information related to state or local influenza activity, reporting of influenza outbreaks and influenza-related pediatric deaths, and advice concerning outbreak control.

\section{Vaccine Adverse Event Reporting System}

The National Childhood Vaccine Injury Act of 1986 requires health care providers to report any adverse event listed by the vaccine manufacturer as a contraindication to future doses of the vaccine or any adverse event listed in the VAERS Table of Reportable Events Following Vaccination (https://vaers.hhs. gov/docs/VAERS_Table_of_Reportable_Events_Following Vaccination.pdf) that occurs within the specified time period after vaccination. In addition to mandated reporting, health care providers are encouraged to report any clinically significant adverse event after vaccination to VAERS. Information on how to report a vaccine adverse event is available at https://vaers. hhs.gov/index.html.

\section{National Vaccine Injury Compensation Program}

The National Vaccine Injury Compensation Program (VICP), established by the National Childhood Vaccine Injury Act of 1986, as amended, provides a mechanism through which compensation can be paid on behalf of a person determined to have been injured or to have died as a result of receiving a vaccine covered by VICP. The Vaccine Injury Table (https:// www.hrsa.gov/sites/default/files/vaccinecompensation/ vaccineinjurytable.pdf) lists the vaccines covered by VICP and the associated injuries and conditions (including death) that might receive a legal presumption of causation. If the injury 
or condition is not in the Table, or does not occur within the specified time period in the Table, persons must prove that the vaccine caused the injury or condition. Eligibility for compensation is not affected by whether a covered vaccine is used off-label or inconsistently with recommendations.

To be eligible for compensation under VICP, a claim must be filed within 3 years after the first symptom of the vaccine injury. Death claims must be filed within 2 years of the vaccinerelated death and not more than 4 years after the start of the first symptom of the vaccine-related injury from which the death occurred. When a new vaccine or a new injury/condition is added to the Table, claims that do not meet the general filing guidelines must be filed within 2 years from the date the vaccine or injury/condition is added to the Table for injuries or deaths that occurred up to 8 years before the Table change (109). Persons of all ages who receive a VICP-covered vaccine might be eligible to file a claim. Additional information is available at https://www.hrsa.gov/vaccine-compensation/index.html or by calling 1-800-338-2382.

\section{Additional Resources}

\section{ACIP Statements}

- General Best Practice Guidelines for Immunization: Best Practices Guidance of the Advisory Committee on Immunization Practices (ACIP). https://www.cdc.gov/ vaccines/hcp/acip-recs/general-recs/index.html

- Immunization of Health-Care Personnel: Recommendations of the Advisory Committee on Immunization Practices (ACIP), 2011. MMWR Recomm Rep 2011;60(No. RR-7). https://www.cdc.gov/mmwr/preview/mmwrhtml/ rr6007a1.htm

- Recommended Adult Immunization Schedules for Ages 19 Years or Older, United States. https://www.cdc.gov/ vaccines/schedules/hcp/adult.html

- Recommended Child and Adolescent Immunization Schedule for Ages 18 Years or Younger, United States. https://www.cdc.gov/vaccines/schedules/hcp/childadolescent.html

\section{Vaccine Information Sheets (VISs)}

- VIS for IIV and RIV4: https://www.cdc.gov/vaccines/hcp/ vis/vis-statements/flu.pdf

- VIS for LAIV4: https://www.cdc.gov/vaccines/hcp/vis/ vis-statements/flulive.pdf

\section{Influenza Vaccine Package Inserts}

- Trivalent Vaccines: https://www.fda.gov/ vaccines-blood-biologics/approved-products/ influenza-virus-vaccine-trivalent-types-and-b

- Quadrivalent Vaccines: https://www.fda.gov/vaccinesblood-biologics/approved-products/ influenza-virus-vaccine-quadrivalent-types-and-types-b

\section{CDC Influenza Antiviral Guidance}

- Influenza Antiviral Medications: Summary for Clinicians: https://www.cdc.gov/flu/professionals/antivirals/ summary-clinicians.htm

\section{American Academy of Pediatrics (AAP) Guidance}

- AAP Recommendations for Prevention and Control of Influenza in Children (Red Book Online): https:// redbook.solutions.aap.org/ss/influenza-resources.aspx

\section{Infectious Diseases Society of America (IDSA) Guidance}

- 2013 IDSA Clinical Practice Guideline for Vaccination of the Immunocompromised Host: https://academic.oup. $\mathrm{com} / \mathrm{cid} /$ article/58/3/e44/336537

\section{American College of Obstetricians and Gynecologists (ACOG)}

- Influenza Vaccination During Pregnancy, ACOG Committee Opinion No. 732: https://www.acog.org/ Clinical-Guidance-and-Publications/CommitteeOpinions/Committee-on-Obstetric-Practice/ Influenza-Vaccination-During-Pregnancy 


\section{References}

1. Barker WH. Excess pneumonia and influenza associated hospitalization during influenza epidemics in the United States, 1970-78. Am J Public Health 1986;76:761-5. https://doi.org/10.2105/AJPH.76.7.761

2. Barker WH, Mullooly JP. Impact of epidemic type A influenza in a defined adult population. Am J Epidemiol 1980;112:798-811. https:// doi.org/10.1093/oxfordjournals.aje.a113052

3. Poehling KA, Edwards KM, Griffin MR, et al. The burden of influenza in young children, 2004-2009. Pediatrics 2013;131:207-16. https:// doi.org/10.1542/peds.2012-1255

4. Poehling KA, Edwards KM, Weinberg GA, et al; New Vaccine Surveillance Network. The underrecognized burden of influenza in young children. N Engl J Med 2006;355:31-40. https://doi. org/10.1056/NEJMoa054869

5. Siston AM, Rasmussen SA, Honein MA, et al; Pandemic H1N1 Influenza in Pregnancy Working Group. Pandemic 2009 influenza A(H1N1) virus illness among pregnant women in the United States. JAMA 2010;303:1517-25. https://doi.org/10.1001/jama.2010.479

6. Mullooly JP, Bridges CB, Thompson WW, et al; Vaccine Safety Datalink Adult Working Group. Influenza- and RSV-associated hospitalizations among adults. Vaccine 2007;25:846-55. https://doi.org/10.1016/j. vaccine.2006.09.041

7. Coleman BL, Fadel SA, Fitzpatrick T, Thomas SM. Risk factors for serious outcomes associated with influenza illness in high- versus lowand middle-income countries: Systematic literature review and metaanalysis. Influenza Other Respir Viruses 2018;12:22-9. https://doi. org/10.1111/irv. 12504

8. Van Wormer JJ, King JP, Gajewski A, McLean HQ, Belongia EA. Influenza and Workplace Productivity Loss in Working Adults. J Occup Environ Med 2017;59:1135-9. https://doi.org/10.1097/ JOM.0000000000001120

9. Willis GA, Preen DB, Richmond PC, et al; WAIVE Study Team. The impact of influenza infection on young children, their family and the health care system. Influenza Other Respir Viruses 2019;13:18-27. https://doi.org/10.1111/irv.12604

10. Fragaszy EB, Warren-Gash C, White PJ, et al; Flu Watch Group. Effects of seasonal and pandemic influenza on health-related quality of life, work and school absence in England: results from the Flu Watch cohort study. Influenza Other Respir Viruses 2018;12:171-82. https://doi. org/10.1111/irv.12506

11. Fiore AE, Uyeki TM, Broder K, et al; Centers for Disease Control and Prevention (CDC). Prevention and control of influenza with vaccines: recommendations of the Advisory Committee on Immunization Practices (ACIP), 2010. MMWR Recomm Rep 2010;59(RR-8).

12. CDC. How flu vaccine effectiveness and efficacy is measured: questions and answers. Atlanta, GA: US Department of Health and Human Services, CDC. https://www.cdc.gov/flu/professionals/vaccination/ effectivenessqa.htm

13. Rolfes MA, Foppa IM, Garg S, et al. Annual estimates of the burden of seasonal influenza in the United States: a tool for strengthening influenza surveillance and preparedness. Influenza Other Respir Viruses 2018;12:132-7. https://doi.org/10.1111/irv.12486

14. Rolfes MA, Flannery B, Chung J, et al; US Flu VE Network, the Influenza Hospitalization Surveillance Network (FluSurv-NET), and the Assessment Branch, Immunization Services Division, CDC. Effects of Influenza Vaccination in the United States during the 2017-2018 Influenza Season. Clin Infect Dis 2019. https://doi.org/10.1093/cid/ciz075

15. Grohskopf LA, Sokolow LZ, Broder KR, Walter EB, Fry AM, Jernigan DB. Prevention and Control of Seasonal Influenza with Vaccines: Recommendations of the Advisory Committee on Immunization PracticesUnited States, 2018-19 Influenza Season. MMWR Recomm Rep 2018;67(No. RR-3). https://doi.org/10.15585/mmwr.rr6703a1
16. CDC. The flu season. Atlanta, GA: US Department of Health and Human Services, CDC; 2015. https://www.cdc.gov/flu/about/season/ flu-season.htm

17. Castilla J, Martínez-Baz I, Martínez-Artola V, et al; Primary Health Care Sentinel Network; Network for Influenza Surveillance in Hospitals of Navarre. Decline in influenza vaccine effectiveness with time after vaccination, Navarre, Spain, season 2011/12. Euro Surveill 2013;18:20388. https://doi.org/10.2807/ese.18.05.20388-en

18. Kissling E, Valenciano M, Larrauri A, et al. Low and decreasing vaccine effectiveness against influenza $\mathrm{A}(\mathrm{H} 3)$ in $2011 / 12$ among vaccination target groups in Europe: results from the I-MOVE multicentre casecontrol study. Euro Surveill 2013;18:20390. https://doi.org/10.2807/ ese.18.05.20390-en

19. Belongia EA, Sundaram ME, McClure DL, Meece JK, Ferdinands J, VanWormer JJ. Waning vaccine protection against influenza A (H3N2) illness in children and older adults during a single season. Vaccine 2015;33:246-51. https://doi.org/10.1016/j.vaccine.2014.06.052

20. Radin JM, Hawksworth AW, Myers CA, Ricketts MN, Hansen EA, Brice GT. Influenza vaccine effectiveness: Maintained protection throughout the duration of influenza seasons 2010-2011 through 2013-2014. Vaccine 2016;34:3907-12. https://doi.org/10.1016/j. vaccine.2016.05.034

21. Ferdinands JM, Fry AM, Reynolds S, et al. Intraseason waning of influenza vaccine protection: Evidence from the US Influenza Vaccine Effectiveness Network, 2011-12 through 2014-15. Clin Infect Dis 2017;64:544-50.

22. Puig-Barberà J, Mira-Iglesias A, Tortajada-Girbés M, et al; Valencia Hospital Network for the Study of Influenza and other Respiratory Viruses (VAHNSI, Spain). Waning protection of influenza vaccination during four influenza seasons, 2011/2012 to 2014/2015. Vaccine 2017;35:5799-807. https://doi.org/10.1016/j.vaccine.2017.09.035

23. Ray GT, Lewis N, Klein NP, et al. Intra-season waning of influenza vaccine effectiveness. Clin Infect Dis 2018.

24. Kissling E, Nunes B, Robertson C, et al; I-MOVE case-control study team. I-MOVE multicentre case-control study 2010/11 to 2014/15: Is there within-season waning of influenza type/subtype vaccine effectiveness with increasing time since vaccination? Euro Surveill 2016;21:30201. https://doi.org/10.2807/1560-7917.ES.2016.21.16.30201

25. Pebody R, Andrews N, McMenamin J, et al. Vaccine effectiveness of 2011/12 trivalent seasonal influenza vaccine in preventing laboratoryconfirmed influenza in primary care in the United Kingdom: evidence of waning intra-seasonal protection. Euro Surveill 2013;18:20389. https://doi.org/10.2807/ese.18.05.20389-en

26. Petrie JG, Ohmit SE, Truscon R, et al. Modest waning of influenza vaccine efficacy and antibody titers during the 2007-2008 influenza season. J Infect Dis 2016;214:1142-9. https://doi.org/10.1093/infdis/jiw105

27. Ferdinands JM, Alyanak E, Reed C, Fry AM. Waning of influenza vaccine protection: Exploring the trade-offs of changes in vaccination timing among older adults. Clin Infect Dis 2019;ciz452. https://doi. org/10.1093/cid/ciz452

28. Shefer A, Atkinson W, Friedman C, et al. Immunization of health-care personnel: recommendations of the Advisory Committee on Immunization Practices (ACIP). MMWR Recomm Rep 2011;60(No. RR-7).

29. Pearson ML, Bridges CB, Harper SA. Influenza vaccination of healthcare personnel: recommendations of the Healthcare Infection Control Practices Advisory Committee (HICPAC) and the Advisory Committee on Immunization Practices (ACIP). MMWR Recomm Rep 2006;55(No. RR-2).

30. Wright PF, Thompson J, Vaughn WK, Folland DS, Sell SH, Karzon DT. Trials of influenza $\mathrm{A} / \mathrm{New}$ Jersey/76 virus vaccine in normal children: an overview of age-related antigenicity and reactogenicity. J Infect Dis 1977;136(Suppl):S731-41. https://doi.org/10.1093/infdis/136. Supplement_3.S731 
31. Wright PF, Dolin R, La Montagne JR. Summary of clinical trials of influenza vaccines-II. J Infect Dis 1976;134:633-8. https://doi. org/10.1093/infdis/134.6.633

32. Wright PF, Sell SH, Thompson J, Karzon DT. Clinical reactions and serologic response following inactivated monovalent influenza type $\mathrm{B}$ vaccine in young children and infants. J Pediatr 1976;88:31-5. https:// doi.org/10.1016/S0022-3476(76)80722-6

33. Gross PA. Reactogenicity and immunogenicity of bivalent influenza vaccine in one- and two-dose trials in children: a summary. J Infect Dis 1977;136(Suppl):S616-25. https://doi.org/10.1093/infdis/136. Supplement_3.S616

34. Bernstein DI, Zahradnik JM, DeAngelis CJ, Cherry JD. Clinical reactions and serologic responses after vaccination with whole-virus or split-virus influenza vaccines in children aged 6 to 36 months. Pediatrics 1982;69:404-8.

35. Jain VK, Domachowske JB, Wang L, et al. Time to change dosing of inactivated quadrivalent influenza vaccine in young children: evidence from a Phase III, randomized, controlled trial. J Pediatric Infect Dis Soc 2017;6:9-19. https://doi.org/10.1093/jpids/piw068

36. Claeys C, Zaman K, Dbaibo G, et al; Flu4VEC Study Group. Prevention of vaccine-matched and mismatched influenza in children aged 6-35 months: a multinational randomised trial across five influenza seasons. Lancet Child Adolesc Health 2018;2:338-49. https://doi. org/10.1016/S2352-4642(18)30062-2

37. Robertson CA, Mercer M, Selmani A, Klein NP, Jeanfreau R, Greenberg DP. Safety and immunogenicity of a full-dose, split-virion, inactivated, quadrivalent influenza vaccine in healthy children 6-35 months of age: a randomized controlled clinical trial. Pediatr Infect Dis J 2019;38:323-8. https://doi.org/10.1097/ INF.0000000000002227

38. Neuzil KM, Jackson LA, Nelson J, et al. Immunogenicity and reactogenicity of 1 versus 2 doses of trivalent inactivated influenza vaccine in vaccine-naive 5-8-year-old children. J Infect Dis 2006;194:1032-9. https://doi.org/10.1086/507309

39. Allison MA, Daley MF, Crane LA, et al. Influenza vaccine effectiveness in healthy 6- to 21-month-old children during the 2003-2004 season. J Pediatr 2006;149:755-62. https://doi.org/10.1016/j.jpeds.2006.06.036

40. Ritzwoller DP, Bridges CB, Shetterly S, Yamasaki K, Kolczak M, France EK. Effectiveness of the 2003-2004 influenza vaccine among children 6 months to 8 years of age, with 1 vs 2 doses. Pediatrics 2005;116:153-9. https://doi.org/10.1542/peds.2005-0049

41. Eisenberg KW, Szilagyi PG, Fairbrother G, et al; New Vaccine Surveillance Network. Vaccine effectiveness against laboratory-confirmed influenza in children 6 to 59 months of age during the 2003-2004 and 2004-2005 influenza seasons. Pediatrics 2008;122:911-9. https://doi. org/10.1542/peds.2007-3304

42. ACOG Committee on Obstetric Practice. ACOG Committee Opinion No. 732. Influenza vaccination during pregnancy. Obstet Gynecol 2018;131:e109-14 10.1097/AOG.0000000000002588. https://doi. org/10.1097/AOG.0000000000002588

43. ACOG Infectious Disease and Public Health Preparedness Expert Work Group. ACOG Committee Opinion No. 741: Maternal Immunization. Obstet Gynecol 2018;131:e214-7 10.1097/AOG.0000000000002665. https://doi.org/10.1097/AOG.0000000000002662

44. Heikkinen T, Young J, van Beek E, et al. Safety of MF59-adjuvanted A/H1N1 influenza vaccine in pregnancy: a comparative cohort study. Am J Obstet Gynecol 2012;207:177.e1-8.

45. Oppermann M, Fritzsche J, Weber-Schoendorfer C, et al. A(H1N1) v2009: a controlled observational prospective cohort study on vaccine safety in pregnancy. Vaccine 2012;30:4445-52. https://doi.org/10.1016/j. vaccine.2012.04.081

46. Pasternak B, Svanström H, Mølgaard-Nielsen D, et al. Vaccination against pandemic A/H1N1 2009 influenza in pregnancy and risk of fetal death: cohort study in Denmark. BMJ 2012;344:e2794. https://doi. org/10.1136/bmj.e2794
47. Sammon CJ, Snowball J, McGrogan A, de Vries CS. Evaluating the hazard of foetal death following $\mathrm{H} 1 \mathrm{~N} 1$ influenza vaccination; a population based cohort study in the UK GPRD. PLoS One 2012;7:e51734. https://doi.org/10.1371/journal.pone.0051734

48. Chambers CD, Johnson D, Xu R, et al; OTIS Collaborative Research Group. Risks and safety of pandemic H1N1 influenza vaccine in pregnancy: birth defects, spontaneous abortion, preterm delivery, and small for gestational age infants. Vaccine 2013;31:5026-32. https://doi. org/10.1016/j.vaccine.2013.08.097

49. Irving SA, Kieke BA, Donahue JG, et al; Vaccine Safety Datalink. Trivalent inactivated influenza vaccine and spontaneous abortion. Obstet Gynecol 2013;121:159-65. https://doi.org/10.1097/AOG.0b013e318279f56f

50. Huang WT, Tang FW, Yang SE, Chih YC, Chuang JH. Safety of inactivated monovalent pandemic (H1N1) 2009 vaccination during pregnancy: a population-based study in Taiwan. Vaccine 2014;32:6463-8. https://doi.org/10.1016/j.vaccine.2014.09.054

51. Ma F, Zhang L, Jiang R, et al. Prospective cohort study of the safety of an influenza $\mathrm{A}(\mathrm{H} 1 \mathrm{~N} 1)$ vaccine in pregnant Chinese women. Clin Vaccine Immunol 2014;21:1282-7. https://doi.org/10.1128/CVI.00375-14

52. Chambers CD, Johnson DL, Xu R, et al; OTIS Collaborative Research Group. Safety of the 2010-11, 2011-12, 2012-13, and 2013-14 seasonal influenza vaccines in pregnancy: birth defects, spontaneous abortion, preterm delivery, and small for gestational age infants, a study from the cohort arm of VAMPSS. Vaccine 2016;34:4443-9. https:// doi.org/10.1016/j.vaccine.2016.06.054

53.McMillan M, Porritt K, Kralik D, Costi L, Marshall H. Influenza vaccination during pregnancy: a systematic review of fetal death, spontaneous abortion, and congenital malformation safety outcomes. Vaccine 2015;33:2108-17. https://doi.org/10.1016/j.vaccine.2015.02.068

54. Bratton KN, Wardle MT, Orenstein WA, Omer SB. Maternal influenza immunization and birth outcomes of stillbirth and spontaneous abortion: a systematic review and meta-analysis. Clin Infect Dis 2015;60:e11-9. https://doi.org/10.1093/cid/ciu915

55. Donahue JG, Kieke BA, King JP, et al. Association of spontaneous abortion with receipt of inactivated influenza vaccine containing H1N1pdm09 in 2010-11 and 2011-12. Vaccine 2017;35:5314-22. https://doi.org/10.1016/j.vaccine.2017.06.069

56. CDC. Advisory Committee on Immunization Practices summary report: February 27-28, 2019 (meeting minutes). Atlanta, GA: US Department of Health and Human Services, CDC; 2019.

57. DiazGranados CA, Dunning AJ, Jordanov E, Landolfi V, Denis M, Talbot HK. High-dose trivalent influenza vaccine compared to standard dose vaccine in elderly adults: safety, immunogenicity and relative efficacy during the 2009-2010 season. Vaccine 2013;31:861-6. https://doi. org/10.1016/j.vaccine.2012.12.013

58. DiazGranados CA, Dunning AJ, Kimmel M, et al. Efficacy of high-dose versus standard-dose influenza vaccine in older adults. N Engl J Med 2014;371:635-45. https://doi.org/10.1056/NEJMoa1315727

59. DiazGranados CA, Dunning AJ, Robertson CA, Talbot HK, Landolfi V, Greenberg DP; DiazGranados CA. Efficacy and immunogenicity of high-dose influenza vaccine in older adults by age, comorbidities, and frailty. Vaccine 2015;33:4565-71.

60. DiazGranados CA, Robertson CA, Talbot HK, Landolfi V, Dunning AJ, Greenberg DP. Prevention of serious events in adults 65 years of age or older: a comparison between high-dose and standard-dose inactivated influenza vaccines. Vaccine 2015;33:4988-93. https://doi.org/10.1016/j. vaccine.2015.07.006

61. Dunkle LM, Izikson R, Patriarca P, et al; PSC12 Study Team. Efficacy of recombinant influenza vaccine in adults 50 years of age or older. N Engl J Med 2017;376:2427-36. https://doi.org/10.1056/ NEJMoa1608862

62. Van Buynder PG, Konrad S, Van Buynder JL, et al. The comparative effectiveness of adjuvanted and unadjuvanted trivalent inactivated influenza vaccine (TIV) in the elderly. Vaccine 2013;31:6122-8. https:// doi.org/10.1016/j.vaccine.2013.07.059 
63. Falsey AR, Treanor JJ, Tornieporth N, Capellan J, Gorse GJ. Randomized, double-blind controlled phase 3 trial comparing the immunogenicity of high-dose and standard-dose influenza vaccine in adults 65 years of age and older. J Infect Dis 2009;200:172-80. https://doi.org/10.1086/599790

64. US Food and Drug Administration. Clinical review: Fluad. Silver Spring, MD: US Food and Drug Administration; 2015.

65. US Food and Drug Administration. Clinical review: Fluzone High-Dose. Silver Spring, MD: US Food and Drug Administration; 2014.

66. Fluzone High-Dose [Package Insert]. Swiftwater, PA: Sanofi Pasetur; 2019.

67. Young-Xu Y, Van Aalst R, Mahmud SM, et al. Relative vaccine effectiveness of high-dose versus standard-dose influenza vaccines among Veterans Health Administration patients. J Infect Dis 2018;217:1718-27. https://doi.org/10.1093/infdis/jiy088

68. Shay DK, Chillarige Y, Kelman J, et al. Comparative effectiveness of high-dose versus standard-dose influenza vaccines among US Medicare beneficiaries in preventing postinfluenza deaths during 2012-2013 and 2013-2014. J Infect Dis 2017;215:510-7. https://doi.org/10.1093/ infdis/jiw641

69. Izurieta HS, Thadani N, Shay DK, et al. Comparative effectiveness of high-dose versus standard-dose influenza vaccines in U.S. residents aged 65 years and older from 2012 to 2013 using Medicare data: a retrospective cohort analysis. Lancet Infect Dis 2015;15:293-300. https://doi.org/10.1016/S1473-3099(14)71087-4

70. Richardson DM, Medvedeva EL, Roberts CB, Linkin DR; CDC Epicenter Program. Comparative effectiveness of high-dose versus standard-dose influenza vaccination in community-dwelling veterans. Clin Infect Dis 2015;61:171-6. https://doi.org/10.1093/cid/civ261

71. Gravenstein S, Davidson HE, Taljaard M, et al. Comparative effectiveness of high-dose versus standard-dose influenza vaccination on numbers of US nursing home residents admitted to hospital: a cluster-randomised trial. Lancet Respir Med 2017;5:738-46. https://doi.org/10.1016/ S2213-2600(17)30235-7

72. Lee JKH, Lam GKL, Shin T, et al. Efficacy and effectiveness of high-dose versus standard-dose influenza vaccination for older adults: a systematic review and meta-analysis. Expert Rev Vaccines 2018;17:435-43. https:// doi.org/10.1080/14760584.2018.1471989

73. US Food and Drug Administration. Summary basis for regulatory action: Flublok Quadrivalent. Silver Spring, MD: US Food and Drug Administration; 2016.

74. Mannino S, Villa M, Apolone G, et al. Effectiveness of adjuvanted influenza vaccination in elderly subjects in northern Italy. Am J Epidemiol 2012;176:527-33. https://doi.org/10.1093/aje/kws313

75. Lapi F, Marconi E, Simonetti M, et al. Adjuvanted versus nonadjuvanted influenza vaccines and risk of hospitalizations for pneumonia and cerebro/cardiovascular events in the elderly. Expert Rev Vaccines 2019;18:663-70. https://doi.org/10.1080/14760584.2019.1622418

76. Ezeanolue E, Harriman K, Hunter P, Kroger A, Pellegrini C. General best practice guidelines for immunization. Best practices guidance of the Advisory Committee on Immunization Practices (ACIP). https://www. cdc.gov/vaccines/hcp/acip-recs/general-recs/downloads/general-recs.pdf

77. Rubin LG, Levin MJ, Ljungman P, et al; Infectious Diseases Society of America. 2013 IDSA clinical practice guideline for vaccination of the immunocompromised host. Clin Infect Dis 2014;58:e44-100. https:// doi.org/10.1093/cid/cit684

78. CDC. Influenza antiviral medications: summary for clinicians. Atlanta, GA: US Department of Health and Human Services, CDC. https:// www.cdc.gov/flu/professionals/antivirals/summary-clinicians.htm

79. Erlewyn-Lajeunesse M, Brathwaite N, Lucas JS, Warner JO. Recommendations for the administration of influenza vaccine in children allergic to egg. BMJ 2009;339(sep153):b3680. https://doi.org/10.1136/ bmj.b3680

80. CDC. Advisory Committee on Immunization Practices summary report: June 20-21, 2012 (meeting minutes). Atlanta, GA: US Department of Health and Human Services, CDC; 2012.
81. CDC. Advisory Committee on Immunization Practices summary report: June 19-20, 2013 (meeting minutes). Atlanta, GA: US Department of Health and Human Services, CDC; 2013.

82. Uyeki TM, Zane SB, Bodnar UR, et al; Alaska/Yukon Territory Respiratory Outbreak Investigation Team. Large summertime influenza A outbreak among tourists in Alaska and the Yukon Territory. Clin Infect Dis 2003;36:1095-102. https://doi.org/10.1086/374053

83. Mutsch M, Tavernini M, Marx A, et al. Influenza virus infection in travelers to tropical and subtropical countries. Clin Infect Dis 2005;40:1282-7. https://doi.org/10.1086/429243

84. Ratnam I, Black J, Leder K, et al. Incidence and risk factors for acute respiratory illnesses and influenza virus infections in Australian travellers to Asia. J Clin Virol 2013;57:54-8. https://doi.org/10.1016/j. jcv.2013.01.008

85. Millman AJ, Kornylo Duong K, Lafond K, Green NM, Lippold SA, Jhung MA. Influenza outbreaks among passengers and crew on two cruise ships: A recent account of preparedness and response to an everpresent challenge. J Travel Med 2015;22:306-11. https://doi. org/10.1111/jtm.12215

86. Flumist Quadrivalent [Package Insert]. Gaithersburg, MD: MedImmune; 2019.

87. Kerzner B, Murray AV, Cheng E, et al. Safety and immunogenicity profile of the concomitant administration of ZOSTAVAX and inactivated influenza vaccine in adults aged 50 and older. J Am Geriatr Soc 2007;55:1499-507. https://doi.org/10.1111/j.1532-5415.2007.01397.x

88. Levin MJ, Buchwald UK, Gardner J, et al. Immunogenicity and safety of zoster vaccine live administered with quadrivalent influenza virus vaccine. Vaccine 2018;36:179-85. https://doi.org/10.1016/j. vaccine.2017.08.029

89. Frenck RW Jr, Gurtman A, Rubino J, et al. Randomized, controlled trial of a 13-valent pneumococcal conjugate vaccine administered concomitantly with an influenza vaccine in healthy adults. Clin Vaccine Immunol 2012;19:1296-303. https://doi.org/10.1128/CVI.00176-12

90. Schwarz TF, Flamaing J, Rümke HC, et al. A randomized, double-blind trial to evaluate immunogenicity and safety of 13 -valent pneumococcal conjugate vaccine given concomitantly with trivalent influenza vaccine in adults aged $\geq 65$ years. Vaccine 2011;29:5195-202. https://doi. org/10.1016/j.vaccine.2011.05.031

91. McNeil SA, Noya F, Dionne M, et al. Comparison of the safety and immunogenicity of concomitant and sequential administration of an adult formulation tetanus and diphtheria toxoids adsorbed combined with acellular pertussis (Tdap) vaccine and trivalent inactivated influenza vaccine in adults. Vaccine 2007;25:3464-74. https://doi.org/10.1016/j. vaccine.2006.12.047

92. Nakashima K, Aoshima M, Ohfuji S, et al. Immunogenicity of simultaneous versus sequential administration of a 23 -valent pneumococcal polysaccharide vaccine and a quadrivalent influenza vaccine in older individuals: A randomized, open-label, non-inferiority trial. Hum Vaccin Immunother 2018;14:1923-30. https://doi.org/10. 1080/21645515.2018.1455476

93. Song JY, Cheong HJ, Tsai TF, et al. Immunogenicity and safety of concomitant MF59-adjuvanted influenza vaccine and 23-valent pneumococcal polysaccharide vaccine administration in older adults. Vaccine 2015;33:4647-52. https://doi.org/10.1016/j.vaccine.2015.05.003

94. Sukumaran L, McCarthy NL, Kharbanda EO, et al. Safety of tetanus toxoid, reduced diphtheria toxoid, and acellular pertussis and influenza vaccinations in pregnancy. Obstet Gynecol 2015;126:1069-74. https:// doi.org/10.1097/AOG.0000000000001066

95. Stockwell MS, Broder K, LaRussa P, et al. Risk of fever after pediatric trivalent inactivated influenza vaccine and 13-valent pneumococcal conjugate vaccine. JAMA Pediatr 2014;168:211-9. https://doi. org/10.1001/jamapediatrics.2013.4469 
96. Duffy J, Weintraub E, Hambidge SJ, et al; Vaccine Safety Datalink. Febrile seizure risk after vaccination in children 6 to 23 months. Pediatrics 2016;138:e20160320. https://doi.org/10.1542/ peds.2016-0320

97. Li R, Stewart B, McNeil MM, et al. Post licensure surveillance of influenza vaccines in the Vaccine Safety Datalink in the 2013-2014 and 2014-2015 seasons. Pharmacoepidemiol Drug Saf 2016;25:928-34. https://doi.org/10.1002/pds.3996

98. Patterson JL, Carapetian SA, Hageman JR, Kelley KR. Febrile seizures. Pediatr Ann 2013;42:249-54. https://doi. org/10.3928/00904481-20131122-09

99. Nolan T, Bernstein DI, Block SL, et al; LAIV Study Group. Safety and immunogenicity of concurrent administration of live attenuated influenza vaccine with measles-mumps-rubella and varicella vaccines to infants 12 to 15 months of age. Pediatrics 2008;121:508-16. https:// doi.org/10.1542/peds.2007-1064

100. Lum LC, Borja-Tabora CF, Breiman RF, et al. Influenza vaccine concurrently administered with a combination measles, mumps, and rubella vaccine to young children. Vaccine 2010;28:1566-74. https:// doi.org/10.1016/j.vaccine.2009.11.054

101. Schwarz TF, Aggarwal N, Moeckesch B, et al. Immunogenicity and safety of an adjuvanted herpes zoster subunit vaccine coadministered with seasonal influenza vaccine in adults aged 50 years or older. J Infect Dis 2017;216:1352-61.
102. Flucelvax Quadrivalent [Package Insert]. Holly Springs, NC: Seqirus; 2019. 103. Fluad [Package Insert]. Holly Springs, NC: Seqirus; 2019.

104. Afluria Quadrivalent [Package Insert]. Parkville, Victoria, Australia: Seqirus; 2019.

105. US Food and Drug Administration. Clinical review: Afluria Quadrivalent. Silver Spring, MD: US Food and Drug Administration; 2018.

106. Statler VA, Albano FR, Airey J, et al. Immunogenicity and safety of a quadrivalent inactivated influenza vaccine in children 6-59 months of age: A phase 3, randomized, noninferiority study. Vaccine 2019;37:343-51. https://doi.org/10.1016/j.vaccine.2018.07.036

107. Fluzone Quadrivalent [Package Insert]. Swiftwater, PA: Sanofi Pasteur; 2019.

108. US Food and Drug Administration. Clinical review: Fluzone Quadrivalent. Silver Spring, Maryland: US Food and Drug Administration; 2019.

109. Health Resources and Services Administration. What you need to know about the National Vaccine Injury Compensation Program (VICP). Washington, DC: US Department of Health and Human Services, Health Resources and Services Administration; 2019. https://www. hrsa.gov/sites/default/files/hrsa/vaccine-compensation/resources/ about-vaccine-injury-compensation-program-booklet.pdf

\section{Disclosure of Relationship}

The authors each report that they have nothing to disclose. This report includes discussion of the unlabeled use of influenza vaccines in the instance of influenza vaccination of persons with a history of egg allergy. A history of severe allergic reaction to the vaccine or any of its components (which include egg for some vaccines) is a labeled contraindication to receipt of most IIVs and LAIV4. However, ACIP and CDC recommended that persons with a history of allergic reaction of any severity to egg should receive any licensed, recommended influenza vaccine that is appropriate for their age and health status. Persons with a history of severe allergic reaction to egg should be vaccinated in an inpatient or outpatient medical setting (including, but not necessarily limited to, hospitals, clinics, health departments, and physician offices); vaccine administration should be supervised by a health care provider who is able to recognize and manage severe allergic reactions. No postvaccination waiting period is recommended specifically for egg-allergic persons. However, ACIP recommends that vaccine providers consider observing patients (seated or supine) for 15 minutes following administration of any vaccine to decrease the risk for injury should syncope occur. 


\section{Advisory Committee on Immunization Practices (ACIP), July 1, 2018-June 30, 2019}

Chair: José R. Romero, MD, Arkansas Children's Hospital Research Institute, Little Rock, Arkansas.

Executive Secretary: Amanda Cohn, MD, National Center for Immunization and Respiratory Diseases, CDC Atlanta, Georgia.

Members: Robert L. Atmar, MD, Baylor College of Medicine, Houston, Texas; Kevin A. Ault, MD, University of Kansas Medical Center, Kansas City, Kansas; Henry Bernstein, DO, Zucker School of Medicine at Hofstra/Northwell Cohen Children's Medical Center, New Hyde Park, New York; Echezona Ezeanolue, MD, University of Nevada, Las Vegas, Nevada; Sharon E. Frey, MD, Saint Louis University Medical School, Saint Louis, Missouri; Stefan Gravenstein, MD, Providence Veterans Administration Hospital, Providence, Rhode Island; Paul Hunter, MD, City of Milwaukee Health Department, Milwaukee, Wisconsin; Grace M. Lee, MD, Lucile Packard Children's Hospital, Stanford University School of Medicine, Stanford, California; Veronica V. McNally, JD, Franny Strong Foundation, West Bloomfield, Michigan; Kelly Moore, MD, Vanderbilt University School of Medicine, Nashville, Tennessee; David Stephens, MD, Emory University, Atlanta, Georgia; Peter Szilagyi, MD, University of California, Los Angeles, Los Angeles, California; Helen Keipp Talbot, MD, Vanderbilt University, Nashville, Tennessee, Emmanuel (Chip) Walter, MD, Duke University School of Medicine, Durham, North Carolina.

Ex Officio Members: Centers for Medicare and Medicaid Services, Mary Beth Hance, Baltimore, Maryland; Department of Defense, Eric Deussing, MD, Atlanta, Georgia; Department of Veterans Affairs, Jane A. Kim, MD, Durham, North Carolina; Food and Drug Administration, Doran Fink, MD, PhD, Silver Spring, Maryland; Health Resources, and Services Administration, Narayan Nair, MD, Rockville, Maryland; Indian Health Service, Thomas Weiser, MD, Portland, Oregon; National Vaccine Program Office, Tammy Beckham, District of Columbia; National Institutes of Health, John Beigel, MD, Bethesda, Maryland.

Liaison Representatives: American Academy of Family Physicians, Pamela G. Rockwell, DO, Ann Arbor, Michigan; American Academy of Pediatrics, Committee on Infectious Diseases, Yvonne Maldonado, MD, Stanford, California; American Academy of Pediatrics, Red Book Editor, David Kimberlin, MD, Birmingham, Alabama; American Academy of Physician Assistants, Marie-Michèle Léger, MPH, Alexandria, Virginia; American College Health Association, Susan Even, MD, Columbia, Missouri; American College of Nurse Midwives, Carol E. Hayes, MN, MPH, Atlanta, Georgia; American College of Nurse Midwives, (alternate) Pamela M. Meharry, PhD; American College of Obstetricians and Gynecologists, Linda O’Neal Eckert, MD, Seattle, Washington; American College of Physicians, Jason M. Goldman, MD, Boca Raton, Florida; American Geriatrics Society, Kenneth Schmader, MD, Durham, North Carolina; America's Health Insurance Plans, Mark J. Netoskie, MD, Houston, Texas; American Immunization Registry Association, Rebecca Coyle, MSEd, District of Columbia; American Medical Association, Sandra Adamson Fryhofer, MD, Atlanta, Georgia; American Nurses Association, Charles (Chad) Rittle, MPH, Pittsburgh, Pennsylvania; American Osteopathic Association, Stanley E. Grogg, DO, Tulsa, Oklahoma; American Pharmacists Association, Stephan L. Foster, PharmD, Memphis, Tennessee; Association of Immunization Managers, Christine Finley, MPH, Burlington, Vermont; Association for Prevention Teaching and Research, W. Paul McKinney, MD, Louisville, Kentucky; Association of State and Territorial Health Officials, Nathaniel Smith, MD, Little Rock, Arkansas; Biotechnology Industry Organization Phyllis A. Arthur, MBA, District of Columbia; Council of State and Territorial Epidemiologists, Christine Hahn, MD, Boise, Idaho; Canadian National Advisory Committee on Immunization, Caroline Quach, MD, Montreal, Québec, Canada; Infectious Diseases Society of America, Carol J. Baker, MD, Houston, Texas; National Association of County and City Health Officials, Matthew Zahn, MD, Santa Ana, California; National Association of County and City Health Officials, (alternate) Jeffrey Duchin, MD, Seattle, Washington; National Association of Pediatric Nurse Practitioners, Patricia A. Stinchfield, MS, St. Paul, Minnesota; National Foundation for Infectious Diseases, William Schaffner, MD, Nashville, Tennessee; National Immunization Council and Child Health Program, Mexico, Luis Durán, MD, Mexico City, Mexico; National Medical Association, Patricia WhitleyWilliams, MD, New Brunswick, New Jersey; Pediatric Infectious Diseases Society, Sean O’Leary, MD, Aurora, Colorado; Pediatric Infectious Diseases Society (alternate), Mark H. Sawyer, MD, San Diego, California; Pharmaceutical Research and Manufacturers of America, David R. Johnson, MD, Swiftwater, Pennsylvania; Society for Adolescent Health and Medicine, Amy B. Middleman, MD, Oklahoma City, Oklahoma; Society for Healthcare Epidemiology of America, David Weber, MD, Chapel Hill, North Carolina.

Chair: Emmanuel (Chip) Walter, MD, Durham, North Carolina.

\section{ACIP Influenza Vaccine Work Group}

Members: Robert Atmar, MD, Houston, Texas; Kevin Ault, MD, Kansas City, Missouri; Edward Belongia, MD, Marshfield, Wisconsin; Henry Bernstein, DO, Hempstead, New York; Sarah Coles, MD, Phoenix, Arizona; Michael Cooper, PhD, Bethesda, Maryland; Clarence B. Creech, MD, Nashville, Tennessee; Sarah Despres, JD, District of Columbia; Jeff Duchin, MD, Seattle, Washington; Sandra Adamson Fryhofer, MD, Atlanta, Georgia, Ian Gemmill, MD, Kingston, Ontario, Canada; Denise Jamieson, MD, Atlanta, Georgia; Wendy Keitel, MD, Houston, Texas; Marie-Michèle Léger, MPH, Alexandria, Virginia; Susan Lett, MD, Jamaica Plain, Massachusetts; Jamie Loehr, MD, Ithaca, New York; Flor M. Munoz, MD, Houston, Texas; Kathleen M. Neuzil, MD, Baltimore, Maryland; Cynthia Nolletti, MD, Silver Spring, Maryland; Roshan Ramanathan, MD, Silver Spring, Maryland; Chris Roberts, PhD, Bethesda, Maryland; William Schaffner, MD, Nashville, Tennessee; Robert Schechter, MD, Richmond, California; Kenneth Schmader, MD, Durham, North Carolina; Tamara Sheffield, MD, Salt Lake City, Utah; Patricia Stinchfield, MS, St. Paul, Minnesota; Peter Szilagyi, MD, Los Angeles, California; Susan Wollersheim, MD, Silver Spring, Maryland; Kelsey Young, MPH, Ottawa, Ontario, Canada; Matthew Zahn, MD, Santa Anna, California. 




The Morbidity and Mortality Weekly Report (MMWR) Series is prepared by the Centers for Disease Control and Prevention (CDC) and is available free of charge in electronic format. To receive an electronic copy each week, visit MMWR at https://www.cdc.gov/mmwr/index.html.

Readers who have difficulty accessing this PDF file may access the HTML file at https://www.cdc.gov/mmwr/volumes/68/rr/rr6803a1.htm?s_ cid=rr6803a1_w. Address all inquiries about the $M M W R$ Series, including material to be considered for publication, to Executive Editor, $M M W R$ Series, Mailstop E-90, CDC, 1600 Clifton Rd., N.E., Atlanta, GA 30329-4027 or to mmwrq@cdc.gov.

All material in the MMWR Series is in the public domain and may be used and reprinted without permission; citation as to source, however, is appreciated. MMWR and Morbidity and Mortality Weekly Report are service marks of the U.S. Department of Health and Human Services.

Use of trade names and commercial sources is for identification only and does not imply endorsement by the U.S. Department of Health and Human Services.

References to non-CDC sites on the Internet are provided as a service to $M M W R$ readers and do not constitute or imply endorsement of these organizations or their programs by CDC or the U.S. Department of Health and Human Services. CDC is not responsible for the content of these sites. URL addresses listed in $M M W R$ were current as of the date of publication.

ISSN: 0149-2195 (Print) 